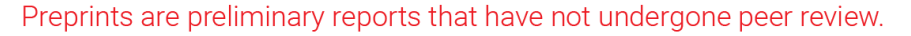 They should not be considered conclusive, used to inform clinical practice, or referenced by the media as validated information. \\ Satellite View of Vegetation Dynamics and Drivers Over Southwestern China
}

\section{Wei Yan}

Beijing Forestry University

\section{Hesong Wang ( $\nabla$ wanghs119@126.com )}

Institute of Forestry and Climate Change Research, Beijing Forestry University, Beijing 100083, China

\section{Chao Jiang}

Beijing Forestry University

\section{Shaofei Jin}

Minjiang University

Jinlong Ai

Yiyang Vocational Technical College

\section{Osbert Jianxin Sun}

Beijing Forestry University

\section{Research}

Keywords: Normalized difference vegetation index (NDVI), vegetation dynamics, climate, human activities, turning point analysis

Posted Date: October 16th, 2020

DOI: https://doi.org/10.21203/rs.3.rs-91188/v1

License: (c) (1) This work is licensed under a Creative Commons Attribution 4.0 International License. Read Full License

Version of Record: A version of this preprint was published at Ecological Indicators on November 1st, 2021. See the published version at https://doi.org/10.1016/j.ecolind.2021.108074. 
1 Satellite view of vegetation dynamics and drivers over Southwestern China

2 Wei Yan ${ }^{1,2}$, Hesong Wang ${ }^{1,2 *}$, Chao Jiang ${ }^{1,2}$, Shaofei $\mathrm{Jin}^{3}$, Jinlong $\mathrm{Ai}^{4}$, Osbert Jianxin Sun ${ }^{1,2}$

3

$4{ }^{1}$ School of Ecology and Nature Conservation, Beijing Forestry University, Beijing 100083, China

$5{ }^{2}$ Institute of Forestry and Climate Change Research, Beijing Forestry University, Beijing 100083,

$6 \quad$ China

$7 \quad{ }^{3}$ Department of Geography, Ocean College, Minjiang University, Fuzhou, 350108, China

$8{ }^{4}$ Department of Biology and Information Engineering, Yiyang Vocational \& Technical College,

$9 \quad$ Yiyang 413049, China

11 *Corresponding author:

12

13

\section{Hesong Wang}

School of Ecology and Nature Conservation, Beijing Forestry University

Beijing 100083, China

Email: wanghs119@126.com

\section{Abstract:}

Background: Vegetation is a key component of terrestrial ecosystems. The dynamics of vegetation can be used as an indicator of vegetation health and ecosystem stability. However, the dynamics and responses of vegetation in Southwestern China remain unclear.

Methods: Both monotonic and turning point approaches were used in trend analysis to understand the dynamics of vegetation. We applied partial correlation analysis and the relative importance of 
climatic factors to determine the drivers of vegetation dynamics. Residual trend analysis was applied to distinguish other drivers.

Results: The annual mean NDVI generally increased at a rate of 0.0011 year $^{-1}$ from 1982 to 2015 , but much of the study area showed the opposite trend before and after the turning point during this period. The vegetation in the western part of the study area was degraded and increased significantly in the eastern part of the study area. An increasing trend that continued to an increasing trend (II) and a decreasing trend that changed into an increasing trend (DI) were two of the largest patterns of vegetation trends, and they were mainly distributed in the eastern part of the study area. An increasing trend that changed into a decreasing trend (ID) was mainly distributed in the western part of the study area, where the vegetation types were mainly evergreen needle-leaved and grassland. Temperature was the dominant climatic factor and had a positive correlation with vegetation in the eastern part of the study area. Temperature also had some negative correlations with vegetation in western mountainous areas where surface soils are prone to droughts. Solar radiation had a positive correlation with vegetation in the western part of the study area. In addition, the regions with more intensity human activities than other areas were concentrated in the eastern part of the study area.

Conclusions: The spatial distribution and trend showed high heterogeneity over Southwestern China. Temperature was the dominant climatic factor. In the eastern part of the study area, human activities played an important role in vegetation greening.

Keywords: Normalized difference vegetation index (NDVI), vegetation dynamics, climate, human activities, turning point analysis 


\section{Introduction}

As a key component of terrestrial ecosystems (Peng et al. 2016), vegetation plays a vital role in regulating cycles of carbon, water, and energy (Cao and Woodward, 1998; Foley et al. 2000; Zoran et al. 2016; Tong et al. 2016), affecting the global climate (Pei et al. 2018), and providing food, fiber and wood production (Liang et al. 2015). Vegetation in an ecosystem is influenced by synergistic effects of climatic change and human activities (Qu et al. 2020; Chu et al. 2019; Hua et al. 2017). The dynamics of vegetation can be used as an indicator of vegetation health and ecosystem stability. Over recent decades, increasing attention has been paid to the observed responses of vegetation dynamics to climate change and human activities (Wang et al. 2020; Zhao et al. 2020; Wang et al. 2020; Jiang et al. 2017; Qu et al. 2018). Therefore, monitoring and attributing the spatiotemporal dynamics of vegetation are critical for understanding the interaction between terrestrial ecosystems and the atmosphere and also for assessing the benefits of strategies and policies for ecosystem restoration (Liu et al. 2019).

Accounting for spatial and temporal heterogeneity, satellite remote sensing provides a great opportunity to map global vegetation information from the Earth's surface (Huete, 2016). The normalized difference vegetation index (NDVI) is widely used as a proxy of vegetation production to track the spatiotemporal dynamics of vegetation ( $\mathrm{Li}$ et al. 2019). Based on satellite-derived NDVI, numerous studies have been conducted to explore and attribute the dynamics of vegetation at various scales (Jeong et al. 2011; Li et al. 2018; Shen et al. 2018; Guo et al. 2018; Jiang et al. 2017). 
Suzuki et al. 2007). Meanwhile, divergent vegetation responses to droughts have been founded. Droughts may promote vegetation growth and carbon absorption in early summer and may lead to a decline in NDVI in spring and winter (Song et al. 2019; Tang and Dubayah, 2017). However, solar radiation has often been neglected. Studies have shown that sufficient solar radiation supplies enough energy for vegetation photosynthesis (Zhang et al. 2016; Fang et al. 2019), and it has some influence on soil moisture (Li et al. 2015; Yang et al. 2015), which may affect vegetation growth (Yao et al. 2017). In addition, increasing attention has been paid to the influence of anthropogenic activities on vegetation change. With the expansion of urbanization, the growth of urban vegetation is affected by the urban heat island effect, human management and other factors, and urbanization may promote or inhibit vegetation growth (Zhong et al. 2019; Liu et al. 2015). The Grain for Green Program has greatly increased vegetation cover and improved the ecological environment of China, especially in the Loess Plateau region (Zhao et al. 2019; Xiao, 2014).

Southwestern China (Fig. 1), including the municipality of Chongqing and the provinces of Sichuan, Yunnan, Guizhou and Guangxi, plays an important role in maintaining biodiversity and state ecosystem security. The western part of this area is mostly dominated by alpine grassland with obvious seasonal and spatial vegetation heterogeneity (Yin et al. 2020; Fu et al. 2014; Rao et al. 2016; Peng et al, 2012). The eastern part is mostly dominated by subtropical vegetation and has formed China's largest terrestrial carbon sink over the last three decades (Piao et al. 2009; Liu et al. 2016). There is a contrasting distribution of the intensity of anthropogenic activities, most of which are concentrated in the eastern part of Southwestern China. Although there are many studies of vegetation dynamics in Southwestern China, many of those studies focused on parts of the study area, such as Yunnan, Guizhou (Hou et al. 2015; Liu et al. 2018), or Sichuan (Peng et al. 2019; Li 
et al. 2020). Almost no studies have investigated all of Southwestern China, and the dynamics and responses of vegetation in this area remain unclear. Additionally, relatively less attention has been paid to anthropogenic activities when attributing vegetation dynamics, and the potential influences of human activities on vegetation growth in Southwestern China are poorly understood.

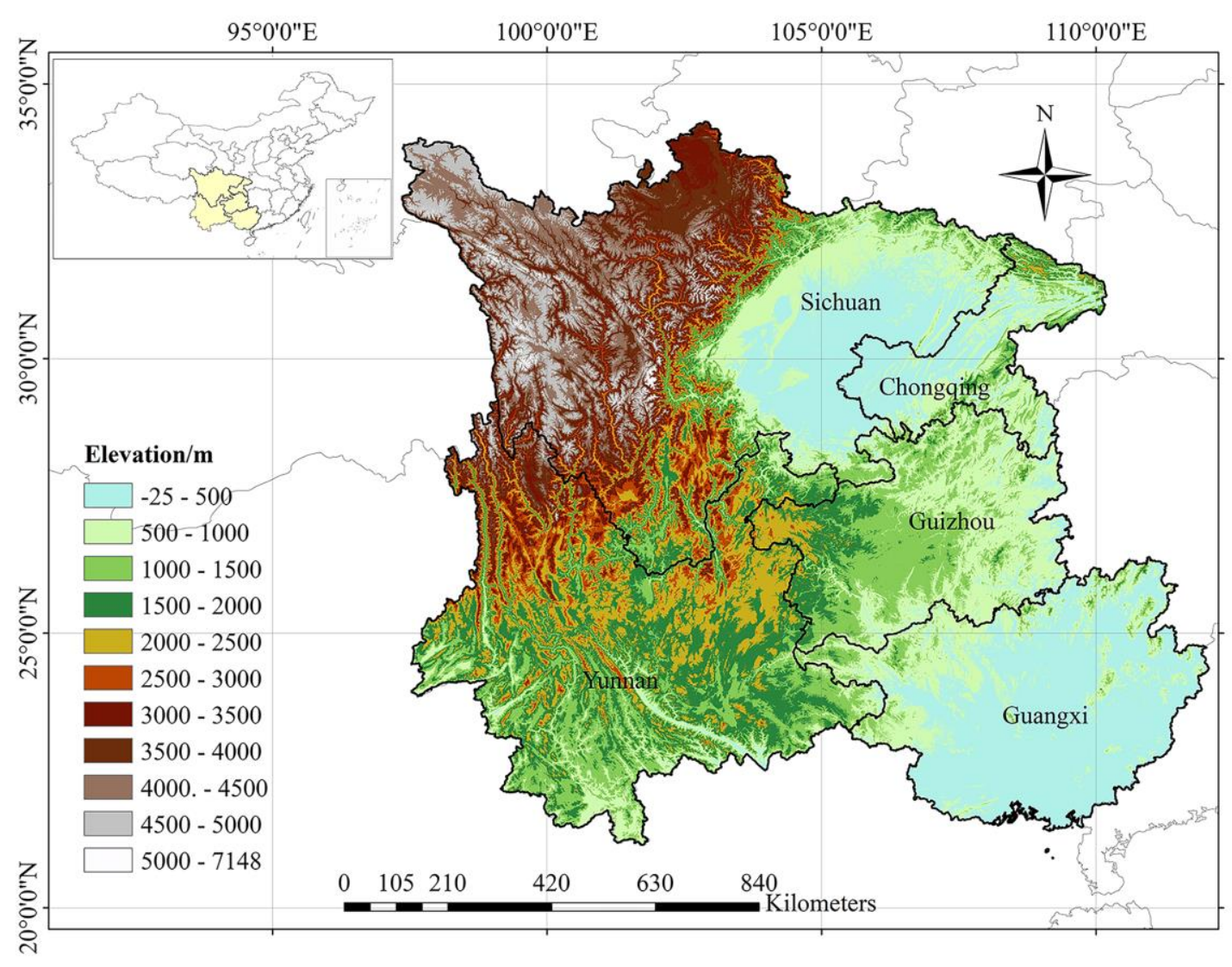

Fig. 1. Location of Southwestern China and a digital elevation model (DEM)

In this study, we used satellite-based NDVI to analyze the spatiotemporal vegetation dynamics and their response to climatic and anthropogenic factors in Southwestern China. Both monotonic approaches and turning point methods were used in the trend analysis of vegetation. The purposes of this study are as follows: (1) to investigate the NDVI and climate factor characteristics of interannual spatiotemporal changes in Southwestern China, (2) to analyze the correlation between NDVI and climatic factors and identify the main drivers at pixel scales and (3) to distinguish other potential drivers of NDVI changes, including human activities and natural disturbance. 


\section{Data and methods}

103

\subsection{Study area}

Southwestern China extends from western Sichuan Plateau to the Beibu Gulf, with an area of 1.37 million $\mathrm{km}^{2}$, accounting for approximately $14.34 \%$ of China's land area (Fig. 1). The elevation varies from $-25-7148 \mathrm{~m}$ and generally increases from east to west. The terrain is complex and includes the Hengduan Mountains, Sichuan Basin, Yunnan-Guizhou Plateau and Guangxi Hills. From east to west, the study area is characterized by a subtropical monsoon climate, tropical seasonal rainforest climate and plateau climate. The monsoon effects and topography together shaped the unevenly distributed climatic factors. The annual mean temperature varies from -11.1$24.56^{\circ} \mathrm{C}$ and decreases from southeast to northwest. The annual mean precipitation varies from 454.55-2731.91mm, and its spatial distribution is generally similar to that of the temperature. The annual mean solar radiation ranges from $115.17-221.62 \mathrm{~W} / \mathrm{m}^{2}$ and increases with increasing elevation. The main vegetation types of the study area include cropland, evergreen broad-leaved forest, deciduous broad-leaved forest, evergreen needle-leaved forest and grassland (Fig. 2a). The population is unevenly distributed and is mainly concentrated in the eastern part (Yu et al. 2018).
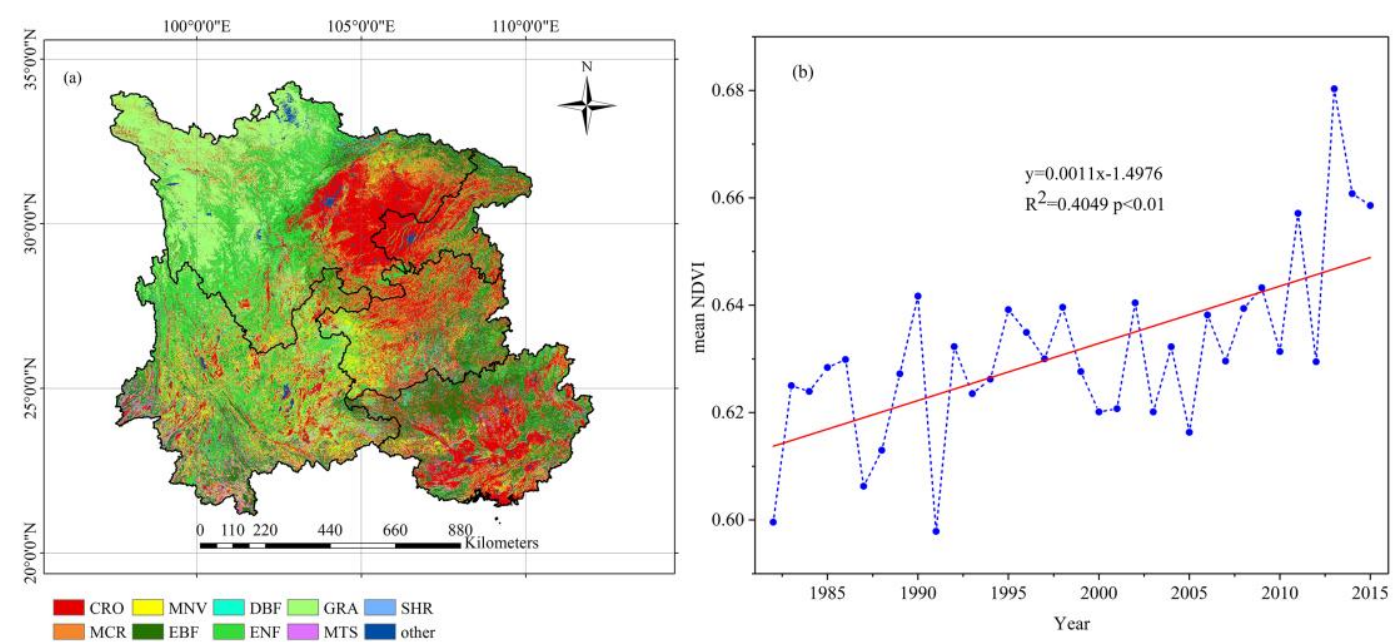

Fig. 2. (a) Spatial distribution of vegetation types and (b) interannual change in mean NDVI in 
Southwestern China over the period 1982-2015. Vegetation types included rainfed and irrigated cropland (CRO); mixed cropland and natural vegetation, cropland $>50 \%(\mathrm{MCR})$; mixed natural vegetation and cropland, natural vegetation $>50 \%(\mathrm{MNV})$; evergreen broad-leaved forest $(\mathrm{EBF})$; deciduous broad-leaved forest (DBF); evergreen needle-leaved forest (ENF); grassland (GRA); mixed tree, shrub and herbaceous vegetation, tree and shrub $>50 \%$ (MTS); shrubland (SHR); wetland, settlement, bare area and water (other).

2.2 Data

\subsubsection{Satellite NDVI}

Advanced Very High Resolution Radiometer (AVHRR) series of satellites record the longest normalized difference vegetation index (NDVI) datasets dating back to 1981 (Tucker et al. 2005). In this study, the NDVI dataset derived from the third generation Global Inventory Monitoring and Modeling System (GIMMS NDVI3g) was adopted to monitor long-term vegetation dynamics. This dataset has a long time span (from 1982 to 2015), its temporal resolution is 15 days, and its spatial resolution is approximately $8 \mathrm{~km}$. The annual NDVI was averaged from May to October, this period is the wet and main growing season for the study area.

\subsubsection{Land cover and DEM}

Land cover map with a $300 \mathrm{~m}$ spatial resolution was acquired from the European Space Agency (ESA) Climate Change Initiative (CCI). Based on this data, different vegetation covers were classified into ten types: rainfed and irrigated cropland (CRO); mixed cropland and natural vegetation, cropland $>50 \%(\mathrm{MCR})$; mixed natural vegetation and cropland, natural vegetation $>$ $50 \%$ (MNV); evergreen broad-leaved forest (EBF); deciduous broad-leaved forest (DBF); evergreen needle-leaved forest (ENF); grassland (GRA); mixed tree, shrub and herbaceous vegetation, tree 
141

and shrub $>50 \%$ (MTS); shrubland (SHR); wetland, settlement, bare area and water (other) (Fig. 2a).

The digital elevation model (DEM) dataset was provided by the Resource Environmental Science Data Center of the Chinese Academy of Sciences with a spatial resolution of $90 \mathrm{~m}$. We resampled the spatial resolution to $8 \mathrm{~km}$ to keep the same resolution as NDVI.

\subsubsection{Climate data}

Climatic datasets, including air temperature, precipitation, and solar radiation, were developed by the Data Assimilation and Modeling Center for Tibetan Multi-spheres, Institute of Tibetan Plateau Research, Chinese Academy of Sciences (http://westdc.westgis.ac.cn/). With a resolution of $10 \mathrm{~km}$ and a long time span from 1979-2015, the dataset is based on existing international Princeton reanalysis data, Global Land Data Assimilation System (GLDAS) data, Global Energy and Water Cycle Experiment-Surface Radiation Budget (GEWEX-SRB) products, and Tropical Rainfall Measuring Mission (TRMM) precipitation data as background fields, combining the routine meteorological observation data of the China Meteorological Administration (He et al. 2020). The monthly average temperature, cumulative precipitation and average solar radiation were resampled to $8 \mathrm{~km}$ for further analysis.

\subsubsection{Human footprint pressure map}

We used a human footprint pressure dataset (https://www.nature.com/articles/sdata201667) to analyze the effects of human activities on vegetation growth. This dataset has a spatial resolution of $1 \mathrm{~km}$ covering both 1993 and 2009. It uses eight variables, including the extent of built environments, population density, electric infrastructure, croplands, pasture lands, roads, railways and navigable waterways, to measure the direct and indirect human pressures on the environment and has been 
163

164

165

used to investigate the impact of human activities on environmental change, such as biodiversity conservation (Venter et al. 2016a) and vegetation dynamics (Li et al. 2018). We used human footprint data for 1993 and 2009 and calculated the difference between 1993 and 2009 to quantify the intensity of human activities.

2.3 Methods

\subsubsection{Trend analysis}

Trend analysis was applied to analyze interannual time series data of NDVI. We used leastsquares linear regression (Eq. 1) to detect the trend of NDVI and climatic factor at the pixel scale.

$$
\text { slope }=\frac{n \sum_{i=1}^{n} i \times Y_{i}-\sum_{i=1}^{n} i \sum_{i=1}^{n} Y_{i}}{n \sum_{i=1}^{n} i^{2}-\left(\sum_{i=1}^{n} i\right)^{2}}
$$

where $Y_{i}$ is NDVI in $i$; $i$ is the year; and $n$ is the total number of years, which is equal to 34; slope is the annual mean increase in NDVI; and slope $>0$ indicates that NDVI had an increasing trend, and vice versa.

Vegetation growth is influenced by climate fluctuations and human activities, and there can be a turning point in vegetation change over a long period. The trend based on least-squares linear regression does not reflect the change characteristics of vegetation in each stage. Therefore, a piecewise linear regression model (Tom and Lesperance, 2003) that has been applied to vegetation dynamics analysis in recent years to further analyze the trend of vegetation change (Eq. 2).

$$
\mathrm{y}=\left\{\begin{array}{lr}
\beta_{0}+\beta_{1} t+\varepsilon & t \leq \alpha \\
\beta_{0}+\beta_{1} t+\beta_{2}(t-\alpha)+\varepsilon & t>\alpha
\end{array}\right.
$$

where $\mathrm{y}$ is NDVI, $t$ is the year, $\alpha$ is the turning point in the trend of NDVI changes, $\beta_{0}$ is the intercept, $\beta_{1}$ is the trend before the turning point, $\beta_{1}+\beta_{2}$ is the trend after the turning point, and $\varepsilon$ is the residual error. Therefore, we can obtain the turning point and the trend before and after the turning point of each pixel. Four types of NDVI changes were observed: an increasing trend that continued to an 
185

186

187

increasing trend (II), an increasing trend that changed into a decreasing trend (ID), a decreasing trend that changed into an increasing trend (DI), and a decreasing trend that continued to a decreasing trend (DD).

\subsubsection{Relationship analysis between NDVI and climatic factors}

Two methods were applied to analyze the relationship between vegetation dynamics and climate change. We applied partial correlation analysis in the $\mathrm{R}$ environment with the package "ppcor" to reflect the relationship between NDVI and climatic factors more realistically. Then, to determine the control factors of vegetation dynamics at the pixel scale, we used the LindemanMerenda-Gold (LMG) approach to calculate the relative importance of temperature, precipitation and solar radiation to NDVI in multiple linear regression in the R environment with the package “relaimpo" (Gromping, 2006). LMG is based on unweighted averages over sequential $\mathrm{R}^{2}$ values of each variable to avoid the order effects of regressors. These metrics decompose $\mathrm{R}^{2}$ into nonnegative contributions that automatically sum to the total $\mathrm{R}^{2}$. When the focus of the research is causal, LMG is more appropriate than other metrics. The relative importance of the three factors was normalized, and the RGB combination was derived to reflect drivers of NDVI change for each pixel.

\subsubsection{Residual trend (RESTREND) analysis}

Human activities is an important driver of vegetation dynamics, like climatic factors. RESTREND analysis can be used to eliminate NDVI changes due to climate change to further analyze vegetation changes caused by human activities. We used precipitation, temperature, and solar radiation to build a multiple linear regression model to obtain a predicted NDVI, and the residuals are the difference between the predicted NDVI and observed NDVI. Using trend analysis to analyze the multiyear residuals, the regions with significant changes may be affected by human 
207

activities, and vegetation changes in areas where the residual changes are not significant can be explained by climate variables (Eq. 3).

$$
N D V I_{\text {pred }_{i}}=a * \text { prec }_{i}+b * \text { temp }_{i}+c * \text { srad }_{i}+d
$$

Where $i$ is the year; $N D V I_{\text {pred }_{i}}$ is the predicted NDVI in $i$; $\operatorname{prec}_{i}$,temp ${ }_{i}$, and $\operatorname{srad}_{i}$ represent the precipitation, temperature and solar radiation in $i$, respectively; $a, b$ and $c$ are regression coefficients; and $d$ is the constant (Eq. 4).

$$
N D V I_{\text {resi }_{i}}=N D V I_{\text {obse }_{i}}-N D V I_{\text {pred }_{i}}
$$

Where $i$ is the year, $N D V I_{\text {pred }_{i}}$ is the predicted NDVI in $i, N D V I_{\text {obse }}$ is the observed NDVI in $i$, and $\quad N D V I_{\text {resi }}$ is the NDVI residual in $i$.

\section{Results}

3.1 Vegetation dynamics over the study area

For the whole study area, the annual mean NDVI showed an increasing trend with a rate of 0.0011 year $^{-1}\left(\mathrm{R}^{2}=0.41, \mathrm{P}<0.01\right)$ from 1982 to 2015 . The annual mean NDVI of Southwestern China ranged from 0.60 in 1991 to 0.68 in 2013 (Fig. 2b). The spatial distribution of NDVI showed high heterogeneity over Southwestern China. The value of NDVI varied from 0.06 to 0.86 and increased from northwest to southeast, and the regions with high values of NDVI $(0.8-0.9)$ were distributed in southern Yunnan, which were MTS, MNV and EBF (Fig. 2a and 3a). The regions with low values of NDVI (0-0.4) were distributed in western Sichuan. The NDVI of most pixels ranged from 0.5 to 0.7, mainly distributed in Sichuan Basin, northern Guizhou and southern Guangxi, which were occupied by $\mathrm{CRO}$ and MCR.

The trend of the spatial distribution of NDVI showed spatial heterogeneity in the study area (Fig. 3b), and NDVI generally increased from 1982 to 2015, with increasing NDVI occupying 82.09\% 

significantly, and the trend of the annual NDVI was as high as 0.016 year $^{-1}$, including CRO in Chongqing, Sichuan and Guizhou, EBF and CRO in Guangxi, and ENF in eastern Yunnan. We also found a small part of regions (17.91\%) in which the NDVI decreased that were located in the and increased significantly in the eastern part of the study area.
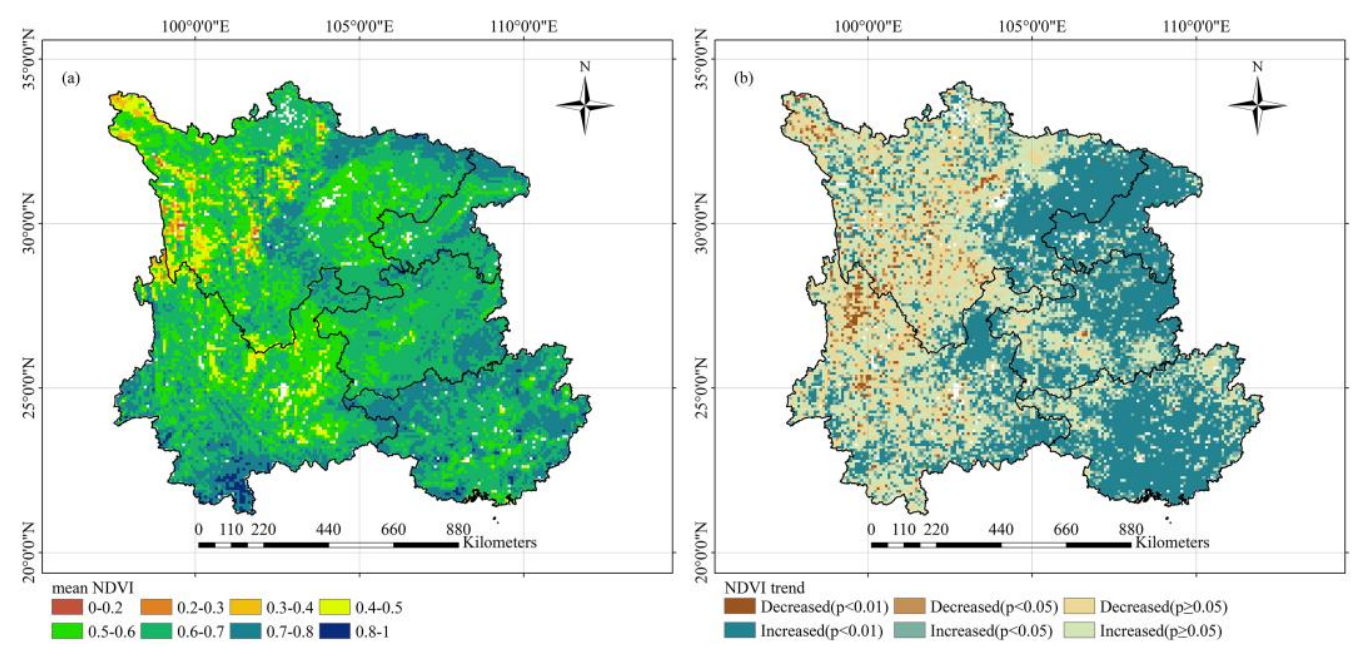

Fig. 3. Spatial distribution of (a) the annual mean NDVI and (b) the NDVI trend over the period

\subsection{Turning points in vegetation trends}

We applied a piecewise linear regression model to further identify turning point years of for $52.02 \%$ of the total pixels and were mainly distributed in the eastern part of the study area and accounted for a large percentage (13.65\%) and were mainly distributed in transition zones between mountains and basins (Fig. 4a). 
Table 1 The percentage of different vegetation types among various NDVI change types

\begin{tabular}{|c|c|c|c|c|}
\hline \multirow{3}{*}{ Vegetation type } & \multicolumn{4}{|c|}{ NDVI change types } \\
\hline & II & ID & DI & DD \\
\hline & \multicolumn{4}{|c|}{ Percentage $(\%)$} \\
\hline CRO & 31.81 & 8.36 & 21.28 & 11.26 \\
\hline MCR & 13.84 & 4.26 & 12.38 & 4.10 \\
\hline MNV & 9.66 & 8.65 & 12.19 & 11.26 \\
\hline EBF & 16.49 & 7.46 & 19.05 & 8.87 \\
\hline DBF & 2.77 & 1.73 & 3.45 & 0.68 \\
\hline ENF & 13.78 & 32.11 & 18.32 & 39.25 \\
\hline MTS & 4.42 & 4.64 & 6.15 & 4.44 \\
\hline GRA & 6.55 & 32.33 & 6.38 & 19.11 \\
\hline SHR & 0.67 & 0.47 & 0.80 & 1.02 \\
\hline Sum & 100.00 & 100.00 & 100.00 & 100.00 \\
\hline
\end{tabular}

252 of Sichuan and karst area of Yunnan, Guizhou and Guangxi, and the vegetation growth in these areas

253 improved significantly. ID was mainly distributed in the western part of the study area, where the

254 vegetation types were mainly ENF and GRA, with an area percentage of $25.44 \%$. DD accounted for 
Table 2 The percentage of different NDVI change types among various vegetation types

\begin{tabular}{|c|c|c|c|c|c|c|c|c|c|}
\hline \multirow{3}{*}{$\begin{array}{l}\text { NDVI } \\
\text { change } \\
\text { type }\end{array}$} & \multicolumn{9}{|c|}{ Vegetation type } \\
\hline & CRO & MCR & MNV & EBF & DBF & ENF & MTS & GRA & SHR \\
\hline & \multicolumn{9}{|c|}{ Percentage $(\%)$} \\
\hline II & 54.66 & 48.27 & 34.99 & 41.19 & 38.24 & 25.16 & 32.47 & 18.49 & 37.29 \\
\hline ID & 9.77 & 10.10 & 21.30 & 12.68 & 16.18 & 39.88 & 23.18 & 62.04 & 17.80 \\
\hline DI & 34.70 & 40.99 & 41.89 & 45.15 & 45.17 & 31.76 & 42.89 & 17.07 & 42.37 \\
\hline $\mathrm{DD}$ & 0.86 & 0.64 & 1.82 & 0.99 & 0.42 & 3.20 & 1.46 & 2.41 & 2.54 \\
\hline Sum & 100 & 100 & 100 & 100 & 100 & 100 & 100 & 100 & 100 \\
\hline
\end{tabular}

258 There was a significant variation in the trend of the vegetation change before and after the

259 turning point in some areas. Before the turning point, $62.84 \%$ of the study area showed an increasing

260 trend, and a decreasing trend was concentrated in the eastern part of the study area (Fig. 4c). After

261 the turning point, the vegetation browned over $27.11 \%$ of the study area, mainly concentrated in

262 western Sichuan Plateau and Hengduan Mountains (Fig. 4d). Vegetation significantly greened in

263 Sichuan Basin and karst areas of Yunnan, Guizhou and Guangxi.

264 Except for ENF and GRA, all the other vegetation types were observed to have a greening 265 trend after the turning point, and the proportion of II exceeded $50 \%$ for CRO (Table 2). A relatively 266 uniform distribution of II, ID and DI were found in ENF. The proportion of ID is as high as $62.04 \%$

267 for GRA, indicating management and restoration are urgent in this area. 


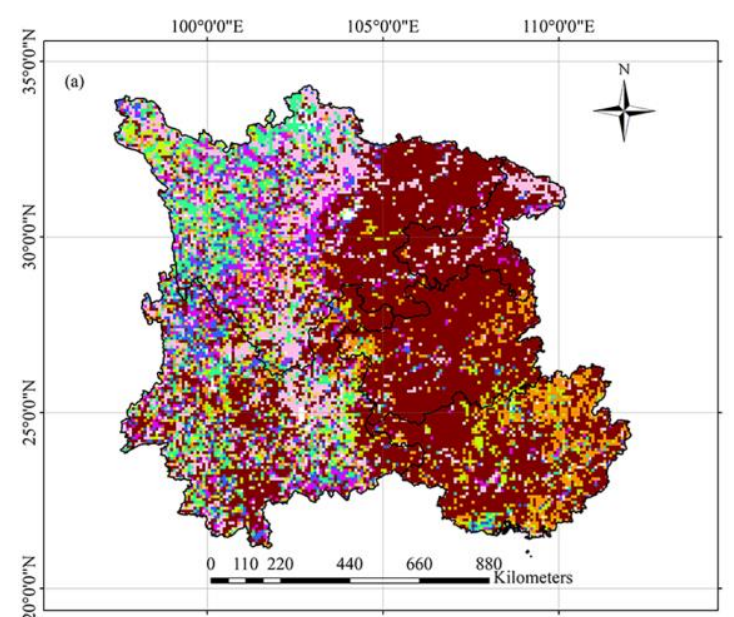

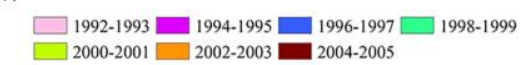

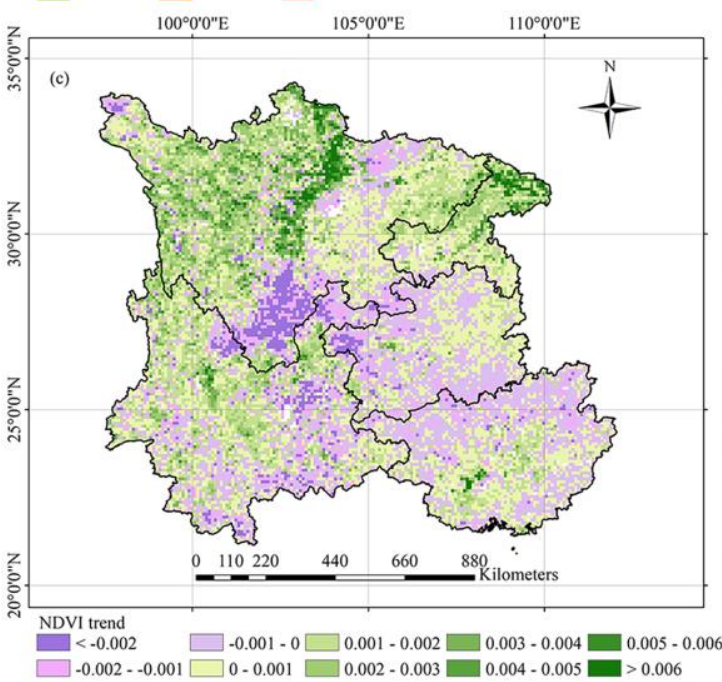

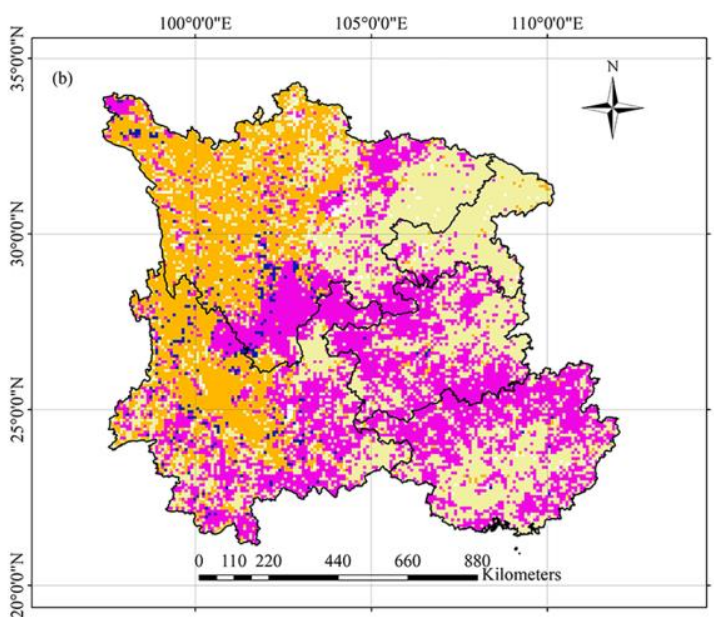

$\square \mathrm{II}(37.40 \%) \square \mathrm{ID}(25.44 \%) \square \mathrm{DI}(35.49 \%) \square \mathrm{DD}(1.67 \%)$

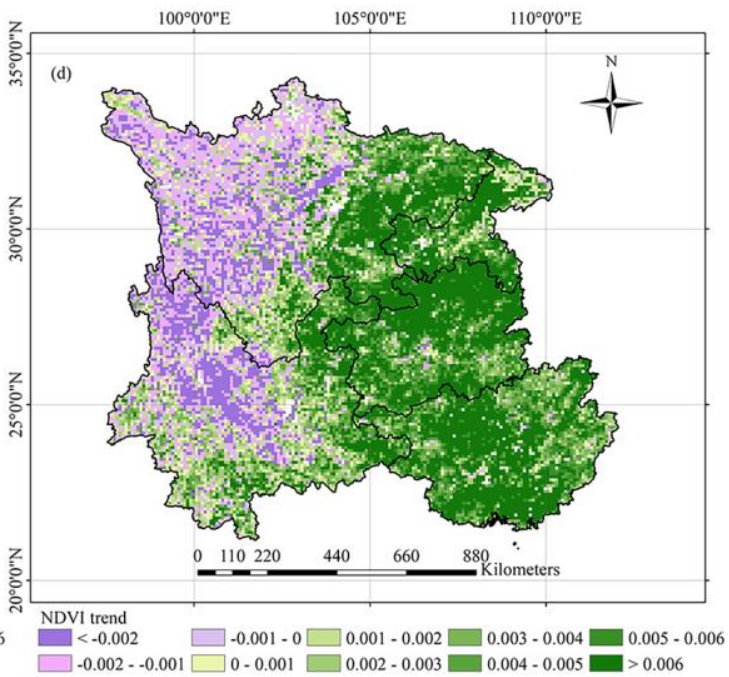

Fig. 4. Spatial distribution of (a) the turning point year, (b) four types of NDVI changes: an

increasing trend that continued to an increasing trend (II), an increasing trend that changed into a

\subsubsection{Driving effects of climatic factors}


279 was calculated at the pixel scale from 1982 to 2015 (Fig. 6a-c). We observed that $71.68 \%$ of the 280 total pixels showed a positive correlation with temperature. These pixels were mainly distributed in 281 the eastern part of the study area, and $24.00 \%$ of the total pixels reached a significant level. In 282 addition, $60.80 \%$ of the NDVI showed a positive correlation with solar radiation, and $8.31 \%$ of the total pixels reached a significant level. They were mainly distributed in the western part of the study area. Further, $57.30 \%$ of the total pixels showed a positive correlation with precipitation, but only $6.22 \%$ of the total pixels reached a significant level and were mainly concentrated in western Chongqing and eastern Guangxi. There were also some negative correlations with climatic factors, mainly in western mountainous areas and eastern karst areas, where surface soils are prone to droughts. 

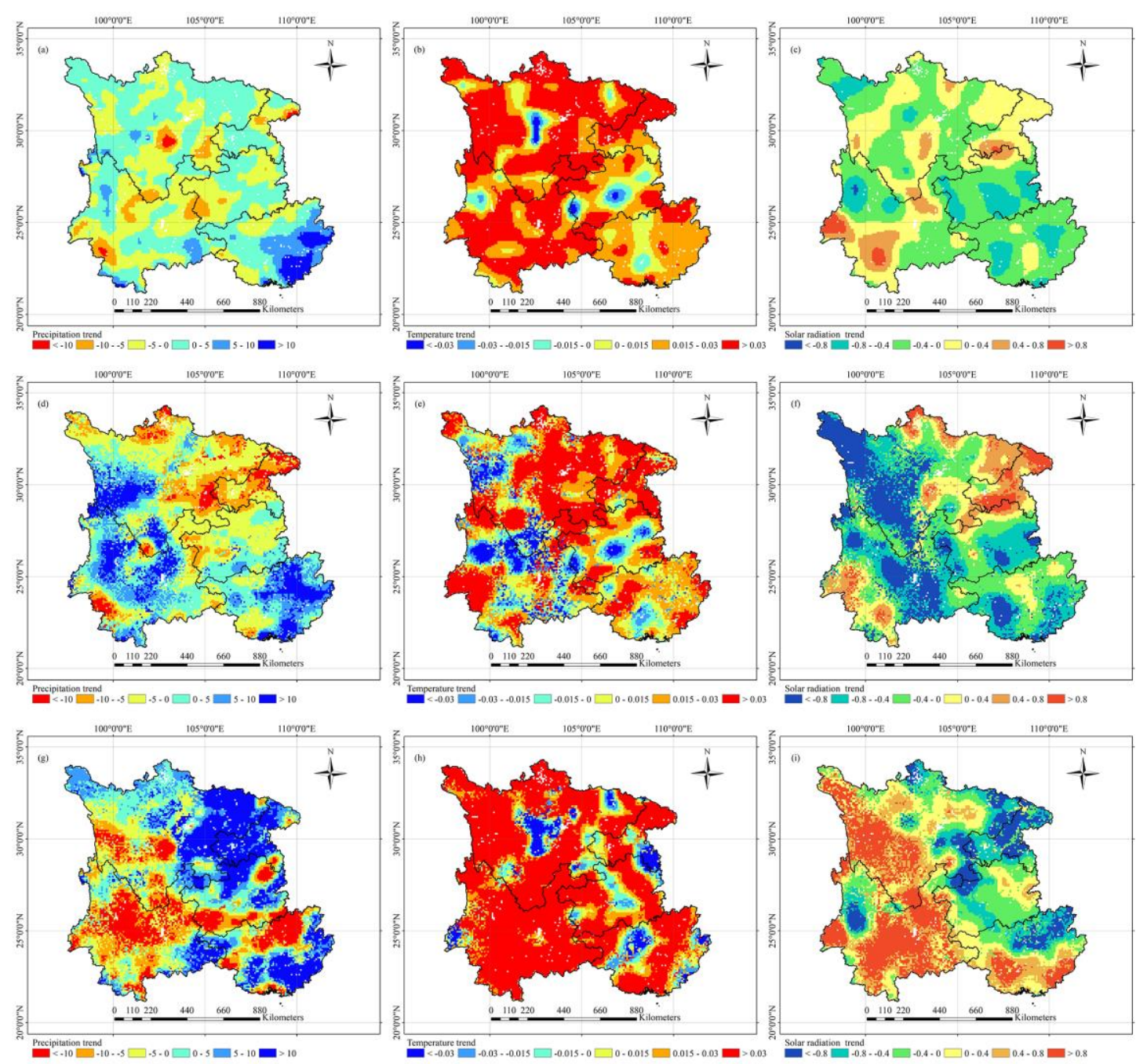

Fig.5. Spatial distribution of (a) the precipitation trend, (b) temperature trend, (c) solar radiation

3.3.2 Dominant climatic factors over the study area

to the NDVI. Overall, the dominant climate driver of NDVI varied widely across the study area.

Regions where temperature was the dominant factor accounted for $47.02 \%$ of the total pixels, while 

main dominant factor were mainly located at the junction of Yunnan and Sichuan, where the
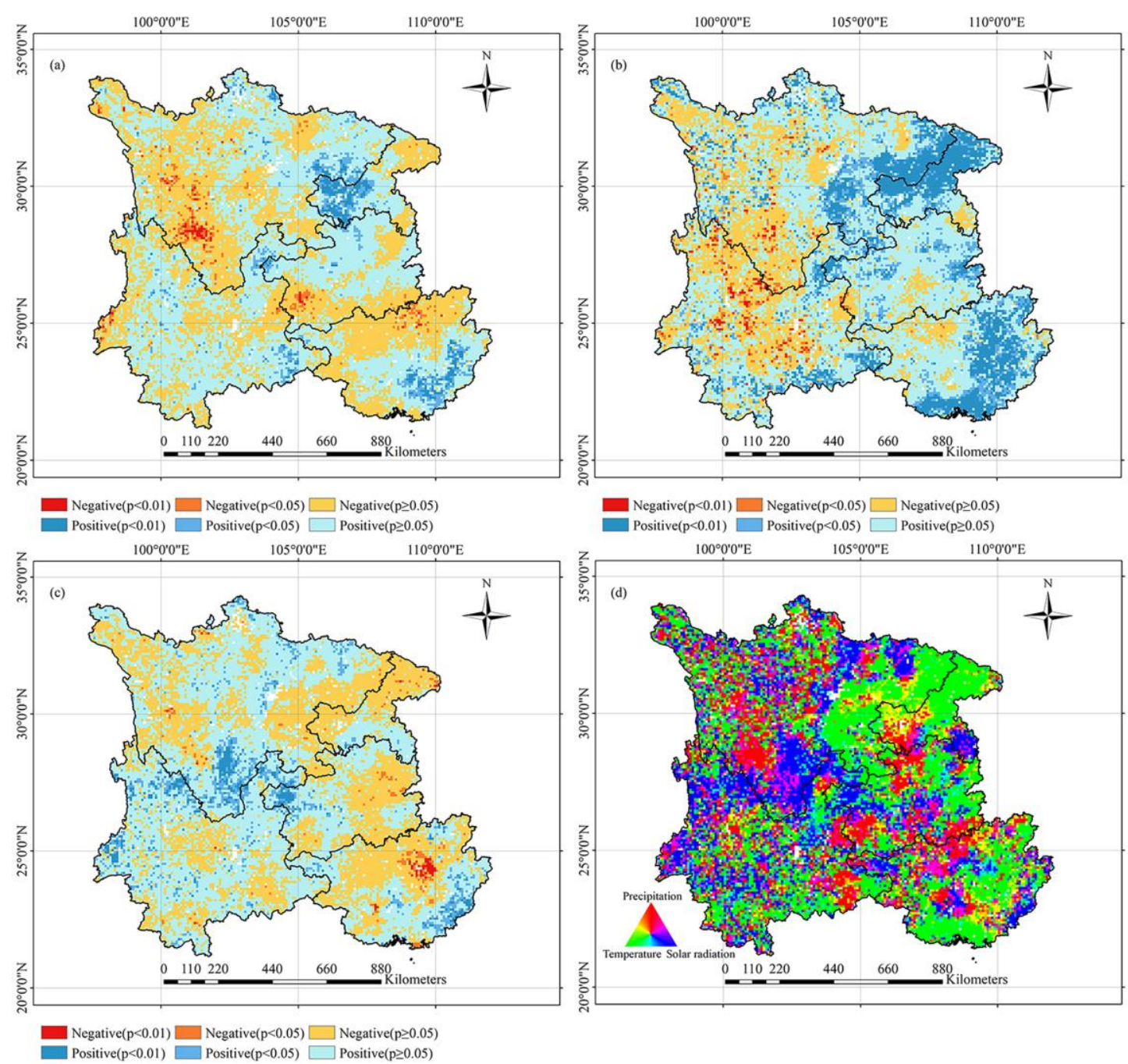

Fig. 6. Spatial distribution of partial correlations between (a) mean NDVI and precipitation, (b) 
mean NDVI and temperature, (c) mean NDVI and solar radiation and (d) climate drivers of NDVI interannual variability.

\subsection{Effects of human activities on vegetation dynamics}

In addition to climatic factors, the impact of human activities on vegetation growth should also be considered. Based on multilinear regression, we analyzed the annual NDVI and climatic factors to calculate the variation trend of NDVI residuals. Residuals represent parts of NDVI that are not explained by precipitation, temperature, or solar radiation. The regions with significant residual variation could not be well explained by the multivariate linear model fitted by temperature, precipitation and solar radiation, and the vegetation changes may be attributed to human activities. In areas where the residuals did not change significantly, vegetation changes were driven by climate variables.

Only $0.72 \%$ of the total pixels residuals decreased significantly, while $29.69 \%$ of the total pixels residuals increased significantly, including in eastern Sichuan, northern Guizhou, western Guangxi and northern Yunnan (Fig. 7a-b). The vegetation types were farmland (CRO, MCR) and EBF. We further analyzed the proportion of the residual variation of different vegetation types (Fig. 7c). We found that $46.02 \%$ of the CRO, $40.30 \%$ of the MCR and $34.34 \%$ of the EBF showed significant residual increases. The proportion of areas with insignificant changes in the residual ENF and GRA was $82.24 \%$ and $88.05 \%$, respectively. These two vegetation types were mainly controlled by climatic factors. Overall, the regions with significant changes in residuals were concentrated in the eastern part of the study area, indicating that human activities played an important role in vegetation growth. In these areas, human afforestation and agriculture activities were intensifying, which lead to the increasing trend of vegetation. 

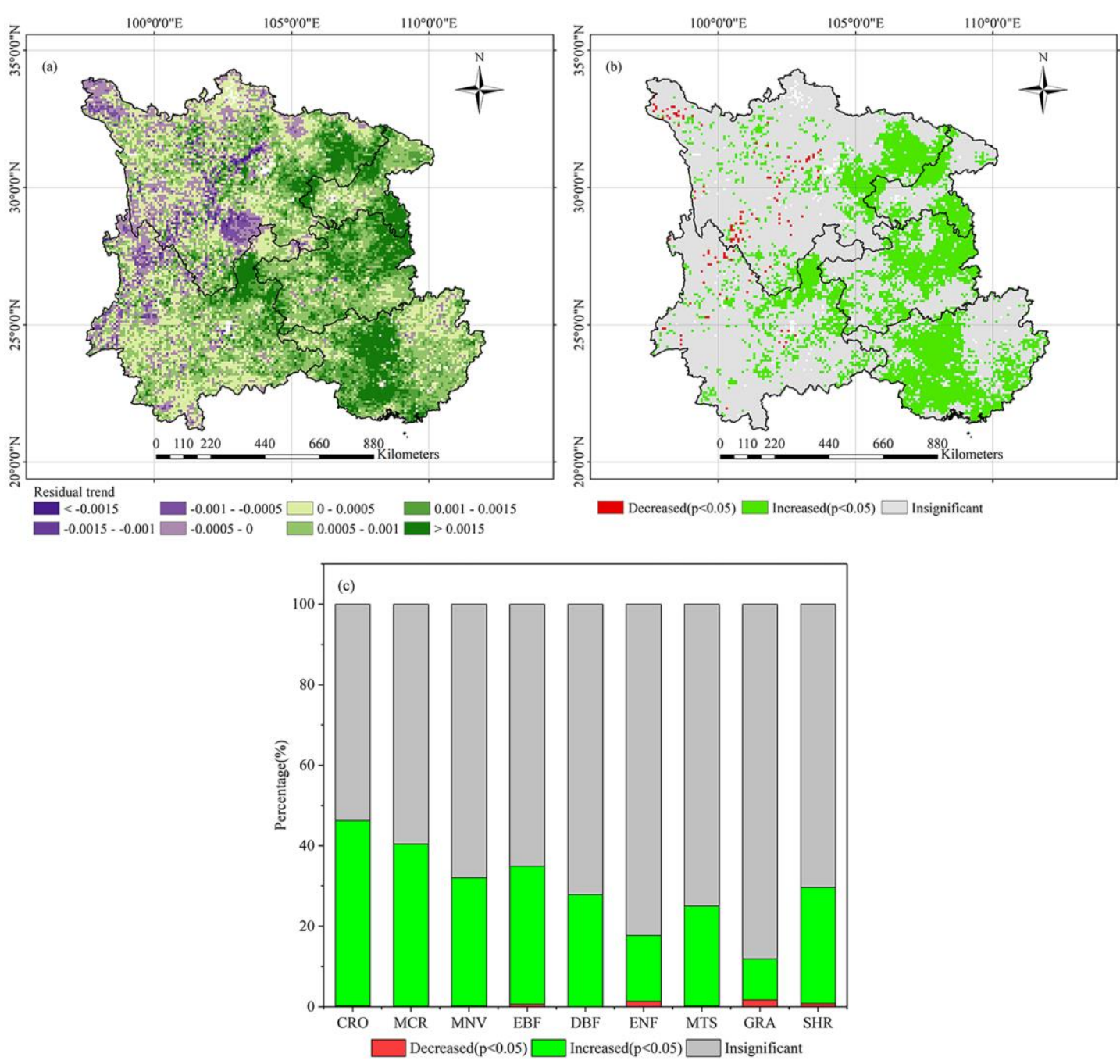

Fig. 7. Spatial distribution of (a) NDVI residual trend and (b) residual trend types; (c) the percentage $(\%)$ of different types of residual trend among vegetation types.

\section{Discussion}

4.1 Climatic factors behind changing patterns of vegetation dynamics

With the longest period of observing global vegetation on satellite, AVHRR series datasets have more than 30 years continuous data to analyze vegetation dynamics. However, it is hard to fully understand the dynamics merely rely on monotonic trend analysis. Recently, more and more nonmonotonic methods were used to further elucidate vegetation dynamics, such as piecewise linear regression models (Cao et al. 2017), breaks for additive seasonal and trend (BFAST) analysis (Fang 
341

342

343

et al. 2018) and Ensemble empirical mode decomposition (EEMD; Pan et al. 2018). It is necessary to fully consider the differences between different periods in the whole study time to describe vegetation dynamics and drivers accurately and completely.

As to our study, $60.93 \%$ of the regions showed opposite changing trends (ID and DI) before and after the turning point, which indicate that the vegetation dynamics in Southwestern China over 34 years were temporal heterogeneity. Drivers behind the turning point of vegetation dynamics are the changing of climatic factors. In the western and the southern parts of the study area, NDVI had a relatively significant turning point, and ID and DI NDVI changes occurred. In western Sichuan Plateau and northern Yunnan, the NDVI increased before the turning point and decreased after the turning point (ID). In this region, vegetation growth was mainly controlled by temperature and precipitation. After the turning point, precipitation in most areas changed from increasing trend to decreasing trend, especially in northern Yunnan (Fig. 5d and g). The region that temperature increased was broader than before the turning point (Fig. 5e and $h$ ). The rapid warming and reduced precipitation caused drought, especially from autumn 2009 to spring 2010 (Wu et al. 2019; Jia et al. 2018; Zhang et al. 2017). Droughts caused by El Niño in 2009-2010 and La Niña in 2012-2013 had a strong impact on vegetation growth (Wang et al. 2015; Wang et al. 2010). In northwestern Yunnan, precipitation decreased, high-quality forests decreased and water storage capacity declined (Xiong et al. 2018). Droughts have emerged in areas that were not dry in the past and may expand over the next 30 years (Zhao et al. 2013). Due to the steep slope of the Hengduan Mountains, precipitation cannot be adequately stored for plant growth, although precipitation has increased in this area.

In southern Sichuan, DI changes of NDVI were observed and were controlled by solar radiation before and after the turning point. Before the turning point, the solar radiation decreased exceeded 
363

364

365

$0.8 \mathrm{~W} \cdot \mathrm{m}^{-2} / \mathrm{yr}$, limiting vegetation growth (Fig. $5 \mathrm{f}$ ). After the turning point, the solar radiation increased exceeded $0.8 \mathrm{~W} \cdot \mathrm{m}^{-2} / \mathrm{yr}($ Fig. 5i) and no longer restricted vegetation growth. In areas where precipitation is not a limiting factor, solar radiation may become the main influential factor (Huete et al. 2006). Karnieli et al. (2010) found that in high latitude and high altitude areas of North America, solar radiation as a control factor of vegetation growth is generally considered to control the beginning or ending of the growing season, mainly affecting the length of the growing season, while temperature was the main control factor in the growing season.

Besides, in the eastern part of the study area, where II NDVI changes occurred, vegetation growth was mainly controlled by temperature. From 1982 to 2015 , the temperature increased exceeded $0.03^{\circ} \mathrm{C} /$ year (Fig. 5b), and the NDVI increased due to the increasing temperature, which advanced the start of the growing season (Shen et al. 2019; Wu et al. 2016).

\subsection{Effects of human activities and limitations of RESTREND}

The population is concentrated in the eastern part of the study area (Yu et al. 2018), where the economy and urbanization has been rapidly developed, and plantation and farmland are strongly affected by human activities. By contrast, the climate in the western part of the study area is dry and cold (Feng et al. 2020), where the development of economic is slow, and the impact of humans on vegetation is weak ( $\mathrm{Qu}$ et al. 2020; Liu et al. 2018). The results of RESTREND analysis also revealed that human activities had a stronger influence on vegetation growth in the eastern part of the study area than in the western part (Fig. 7), which showed a similar spatial pattern with the human footprint pressure map (Fig. 8; Venter et al. 2016b). The high value of the human footprint was mainly concentrated in the central city and radiated in all directions. Because of the mountainous landscape in the western part of Sichuan, the human footprint mainly extended to the 
eastern part. Since 2000, with the implementation of ecological projects such as the Grain for Green Program and Natural Forest Protection Project, which has greatly affected vegetation growth, farmland has decreased, forests have increased, and humans have played an important role in vegetation improvement (Han et al. 2018). Similar results were also found in farmland areas in central and western Guizhou. The central part of Guizhou is a typical karst area, where vegetation is fragile, and the forest has been restored in recent years (Tong et al. 2017). In western Guizhou, the Hurst index exceeded 0.71 , which indicated that the vegetation changed steadily, and the intensity of human agricultural activities in this region was relatively weak (Tian et al. 2017). In the past 20 years, approximately $40 \%$ of the original cultivated land was abandoned, which reduced the negative disturbance to the forest area and reduced pressure on the ecosystem (Han and Song, 2019; Cai et al. 2014; Li et al. 2016). In addition, some forest protection policies and the Karst Rocky Desertification Comprehensive Control and Restoration Project allowed revival of the vegetation (Cheng et al. 2017).

However, the human footprint pressure map and RESTREND analysis results were not completely consistent in some regions. Relevant to our results, in eastern Guangxi, the vegetation types are CRO and EBF, which have not changed significantly in 34 years. RESTREND did not detect the impact of human activities on vegetation growth. However, a large number of Eucalyptus trees were planted here (Lu et al. 2019; Zhang et al. 2019), and human activities are a driving factor of vegetation dynamics. Therefore, issues of RESTREND should be considered when using it to study effects of human activities on vegetation dynamics. One is that factors cannot be explained by climate variables are classified into human factors by RESTREND. Therefore, fires, floods, pests and diseases that cause vegetation dynamic could be mistaken for human activities (Liu et al. 2013; 
This can better detect role of human in driving vegetation dynamics.
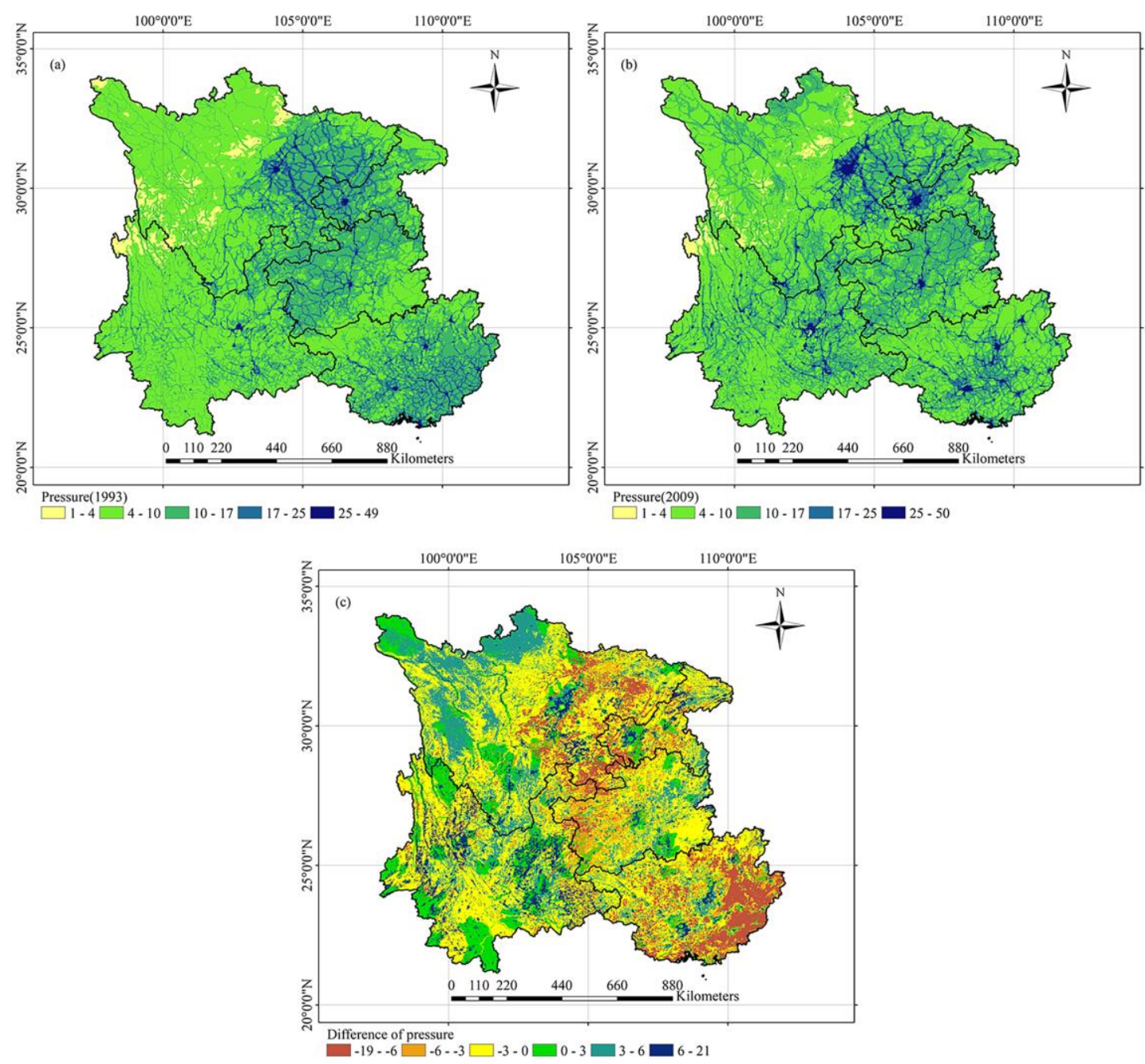
Fig. 8. Spatial distribution of (a) the human footprint map for 1993, (b) the human footprint map for 2009, (c) difference in the human footprint map between 1993 and 2009.

\section{Conclusion}

In view of satellite data, this study analyzed the temporal and spatial dynamics of vegetation across Southwestern China. Based on the results of NDVI trends and driving factors used to detect climate and human activities, several conclusions were drawn as follows. The spatial distribution and trend showed high heterogeneity over Southwestern China. The annual mean NDVI generally increased from 1982-2015, but much of the study area showed the opposite trend before and after the turning point during this period. II and DI were two of the largest patterns of vegetation trends and they were mainly distributed in the eastern part of the study area. Temperature was the dominant climatic factor. In the eastern part of the study area, human activities played an important role in vegetation greening.

\section{Abbreviations}

AVHRR: Advanced Very High Resolution Radiometer; NDVI: normalized difference vegetation index; CRO: rainfed and irrigated cropland; MCR: mixed cropland and natural vegetation, cropland $>50 \% ; \mathrm{MNV}$ : mixed natural vegetation and cropland, natural vegetation $>50 \%$; EBF: evergreen broad-leaved forest; DBF: deciduous broad-leaved forest; ENF: evergreen needle-leaved forest; GRA: grassland; MTS: mixed tree, shrub and herbaceous vegetation, tree and shrub $>50 \%$; SHR: shrubland; II: an increasing trend that continued to an increasing trend; ID: an increasing trend that changed into a decreasing trend; DI: a decreasing trend that changed into an increasing trend; DD: a decreasing trend that continued to a decreasing trend; RESTREND analysis: residual trend analysis 


\section{Declarations}

440 Ethics approval and consent to participate

$441 \quad$ No applicable.

\section{Consent for publication}

443

No applicable.

444

445

446

447

448

449

450

451

452

453

454

455

456

457

458

459

460

\section{Availability of data and materials}

The datasets used and/or analysed during the current study are available from the corresponding author on reasonable request.

\section{Competing interests}

The authors declare that they have no competing interests.

\section{Funding}

This study was supported by the National Key Research and Development Program of China (Grant No. 2016YFC0502104), Natural Science Foundation for Young Scientists of Hunan Province (Grant No. 2020JJ5557) and the National Science Foundation of China (Grant Nos. 41105076; 31770765).

\section{Authors' contributions}

WY, HW \& OJS conceived the study. WY analyzed the data. CJ, SJ \& JA provided technical guidance. WY \& HW wrote the paper. All authors read and approved the final manuscript.

\section{Acknowledgements}

No applicable.

\section{References}

Boever CJ, Dixon MD, Johnson WC, Scott ML, Malloy Jr TP (2019) Effects of a large flood on 
Cai HY, Yang XH, Wang KJ, Xiao LL (2014) Is forest restoration in the southwest China Karst promoted mainly by climate change or human-induced factors? Remote Sens 6(10):9895-9910

Cao M, Woodward FI (1998) Dynamic responses of terrestrial ecosystem carbon cycling to global climate change. Nature 393(6682):249-252

Cao Z, Li YR, Liu YS, Chen YF, Wang YS (2017) When and where did the Loess Plateau turn "green"? Analysis of the tendency and breakpoints of the normalized difference vegetation index. Land Degrad Dev 29:162-175

Cheng F, Lu HF, Ren H, Zhou L, Zhang LH, Li J, Lu XJ, Huang DW, Zhao D (2017) Integrated emergy and economic evaluation of three typical rocky desertification control modes in karst areas of Guizhou Province, China. J Clean Prod 161:1104-1128

Chu HS, Venevsky S, Wu C, Wang MH (2019) NDVI-based vegetation dynamics and its response to climate changes at Amur-Heilongjiang River Basin from 1982 to 2015. Sci Total Environ 650:2051-2062

Fang QL, Zhou L X, Zhu LP, Zhang XJ, Yang J, Zhou J, Song WW, Yu XJ, Luo ZH (2019) Spatiotemporal variation of vegetation dynamics and correlations with climatic factors in the Tibetan Plateau, China. IOP Conf Ser: Earth Environ Sci 346:012015

Fang XQ, Zhu Q, Ren LL, Chen H, Wang K, Peng CH (2018) Large-scale detection of vegetation dynamics and their potential drivers using modis images and bfast: a case study in Quebec, Canada. Remote Sens Environ 206:391-402

Feng L, Yang D, Huang YY (2020) Vegetation NDVI characteristics and response to extreme climate of Sichuan and Chongqing region from 2000 to 2017 (in Chinese). Chinese J Ecol 39(7):2316. 
483

484

485

486

487

488

489

490

491

492

493

494

495

496

497

498

499

500

501

502

503

504

Foley JA, Levis S, Costa MH, Pollard CD (2000) Incorporating dynamic vegetation cover within global climate models. Ecol Appl 10(6):1620-1632

Fu XY, Tang CJ, Zhang XX, Fu JY, Jiang D (2014) An improved indicator of simulated grassland production based on MODIS NDVI and GPP data: A case study in the Sichuan province, China. Ecol Indic 40:102-108

Grömping U (2006) Relative importance for linear regression in r: the package relaimpo. J Stat Softw 17(1):925-933

Guo J, Yang XC, Niu JM, Jin YX, Xu B, Shen G, Zhang WB, Zhao F, Zhang YJ (2018) Remote sensing monitoring of green-up dates in the Xilingol grasslands of northern China and their correlations with meteorological factors. Int J Remote Sens 40:2190-2211

Han R, Cui NX, Guo L (2018) Monitoring the effects of the grain to green projects using landscape metrics: a case study in eastern sichuan, china. IOP Conf Ser: Earth Environ Sci 189:052009

Han Z, Song W (2019) Spatiotemporal variations in cropland abandonment in the Guizhou-Guangxi karst mountain area, China. J Clean Prod 238:117888

He B, Chen AF, Wang HL, Wang QF (2015) Dynamic Response of Satellite-Derived Vegetation Growth to Climate Change in the Three North Shelter Forest Region in China. Remote Sens 7: 9998-10016

He J, Yang K, Tang W, Lu H, Qin J, Chen YY, Li X (2020) The first high-resolution meteorological forcing dataset for land process studies over China. Scientific Data. 7:25.

Hou WJ, Gao JB, Wu SH, Dai EF (2015) Interannual variations in growing-season ndvi and its correlation with climate variables in the southwestern karst region of china. Remote Sens 7(9):11105-11124 
505

506

507

508

509

510

511

512

513

514

515

516

517

518

519

520

521

522

523

524

525

526

Hua WJ, Chen HS, Zhou LM, Xie ZH, Qin MH, Li X, Ma HD, Huang QH, Sun SL (2017) Observational quantification of climatic and human influences on vegetation greening in China. Remote Sens 9:425

Huete A (2016) Vegetation's responses to climate variability. Nature 531:181-182

Huete AR, Didan K, Shimabukuro YE, Ratana P, Saleska SR, Hutyra LR, Yang WZ, Nemani RR, Myneni R (2006) Amazon rainforests green-up with sunlight in dry season. Geophys Res Lett $33(6)$

Jeong JH, Ho CH, Linderholm HW, Jeong SJ, Chen D, Choi YS (2011) Impact of urban warming on earlier spring flowering in Korea. Int J Climatol 17 (7):2385-2399

Jia YQ, Zhang B, Ma B (2018) Daily SPEI Reveals Long-term Change in Drought Characteristics in Southwest China. Chinese Geogr Sci 28:680-693

Jiang LL, Guli J, Bao AM, Guo H, Ndayisaba F (2017) Vegetation dynamics and responses to climate change and human activities in Central Asia. Sci Total Environ 599-600:967-980

Karnieli A, Agam N, Pinker RT, Anderson M, Imhoff ML, Gutman GG, Panov N (2010) Use of ndvi and land surface temperature for drought assessment: merits and limitations. J Climate 23(3):618-633

Li LH, Zhang YL, Liu LS, Wu JS, Wang ZF, Li SC, Zhang HM, Zu JX, Ding MJ, Paudel B (2018) Spatiotemporal patterns of vegetation greenness change and associated climatic and anthropogenic drivers on the tibetan plateau during 2000-2015. Remote Sens 10(10)

Li P, He Z, He D, Xue D, Wang Y, Cao S (2020) Fractional vegetation coverage response to climatic factors based on grey relational analysis during the 2000-2017 growing season in Sichuan Province, China. Int J Remote Sens 41(3):1170-1190 
527

528

Li P, Peng CH, Wang M, Luo YP, Li MX, Zhang KR, Zhang DL, Zhu Q (2018) Dynamics of vegetation autumn phenology and its response to multiple environmental factors from 1982 to 2012 on Qinghai-Tibetan Plateau in China. Sci Total Environ 637-638:855-864

Li SJ, Sun ZG, Tian MH, Li XB (2016) Effects of rural-urban migration on vegetation greenness in fragile areas: A case study of Inner Mongolia in China. J Geogr Sci 26(3): 313-324

Li XY, Li Y, Chen AP, Gao MD, Slette IJ, Piao SL (2019) The impact of the 2009/2010 drought on vegetation growth and terrestrial carbon balance in southwest china. Agric For Meteorol 269

Li Z, Chen YN, Li WH, Deng HJ, Fang GH (2015) Potential impacts of climate change on vegetation dynamics in Central Asia. J Geophys Res-Atmos 120(24):12345-12356

Liang W, Yang YT, Fan DM, Guan HD, Zhang T, Long D, Zhou Y, Bai D (2015) Analysis of spatial and temporal patterns of net primary production and their climate controls in China from 1982 to 2010. Agric For Meteorol 204:22-36.

Liu CC, Liu YG, Guo K, Wang SJ, Liu HM, Zhao HW, Qiao XG, Hou DJ, Li SB (2016) Aboveground carbon stock, allocation and sequestration potential during vegetation recovery in the karst region of southwestern China: a case study at a watershed scale. Agric Ecosyst Environ 235:91-100.

Liu HY, Zhang MY, Lin ZS, Xu XJ (2018) Spatial heterogeneity of the relationship between vegetation dynamics and climate change and their driving forces at multiple time scales in Southwest China. Agric For Meteorol 256-257:10-21

Liu R, Xiao LL, Liu Z, Dai JC (2018) Quantifying the relative impacts of climate and human activities on vegetation changes at the regional scale. Ecol Indic 93:91-99

Liu X, Hu B, Zhang D (2019) Differences in monitoring vegetation dynamics between moderate 
resolution imaging spectroradiometer collection 5 and collection 6 vegetation index products on the loess plateau, china. Int J Remote Sens 40(15-16):5957-5972

551

Liu YX, Wang YL, Peng J, Du YY, Liu XF, Li SS, Zhang DH (2015) Correlations between Urbanization and Vegetation Degradation across the World's Metropolises Using DMSP/OLS Nighttime Light Data. Remote Sens 7:2067-2088

Liu YY, Evans JP, McCabe MF, de Jeu RAM, van Dijk A, Dolman AJ, Saizen I (2013) Changing climate and overgrazing are decimating Mongolian steppes. PLoS One 8

Lu XJ, Huang YH, Yan HB, Zhou L, Wu CL, Zhou B, Luo L (2019) Study on rapid extraction of Eucalyptus vegetation information in Guangxi based on GEE (in Chinese). For. Resour. Manage. 2019(05):52-60+75

Ma QM, Long YP, Jia XP, Wang HB, Li YS (2019) Vegetation response to climatic variation and human activities on the Ordos Plateau from 2000 to 2016. Environ Earth Sci 78(24):709

Pan NQ, Feng XM, Fu BJ, Wang S, Ji F, Pan SF (2018) Increasing global vegetation browning hidden in overall vegetation greening: insights from time-varying trends. Remote Sens Environ 214:59-72

Pei FS, Wu CJ, Liu XP, Xia L, Yang KQ, Zhou Y, Wang K, Xu L, Xia GR (2018) Monitoring the vegetation activity in China using vegetation health indices. Agric For Meteorol 248:215-227

Peng DL, Wu CY, Zhang B, Huete A, Zhang XY, Sun R, Lei LP, Huang WJ, Liu LY, Liu XJ, Li J, Luo SZ, Fang B (2016) The influences of drought and land-cover conversion on inter-annual variation of NPP in the Three-North Shelterbelt Program Zone of China based on MODIS data. PLoS One 11 (6):e0158173

Peng J, Liu YH, Shen H, Han YN, Pan YJ (2012) Vegetation coverage change and associated driving 

forces in mountain areas of Northwestern Yunnan, China using RS and GIS. Environ Monit Assess 184(8):4787-4798

Peng W, Kuang T, Tao S (2019) Quantifying influences of natural factors on vegetation NDVI changes based on geographical detector in Sichuan, western China. J Cleaner Prod 233:353367

Piao SL, Fang JY, Ciais P, Peylin P, Huang Y, Sitch S, Wang T, (2009) The carbon balance of terrestrial ecosystems in China. Nature 458:1009-1013

Piao SL, Mohammat A, Fang JY, Cai Q, Feng JM (2006) NDVI-based increase in growth of temperate grasslands and its responses to climate changes in China. Global Environ. Chang. Hum. Policy Dimens 16:340-348

Qu S, Wang LC, Lin AW, Yu DQ, Yuan M, Li CA (2020) Distinguishing the impacts of climate change and anthropogenic factors on vegetation dynamics in the Yangtze River Basin, China. Ecol Indic 108:105724

Qu S, Wang LC, Lin AW, Zhu HJ, Yuan MX (2018) What drives the vegetation restoration in Yangtze River basin, China: Climate change or anthropogenic factors? Ecol Indic 90:438-450

Rao EM, Xiao Y, Ouyang ZY, Zheng H (2016) Changes in ecosystem service of soil conservation between 2000 and 2010 and its driving factors in southwestern China. Chinese Geogr Sci 26(2):165-173

Shen XJ, Liu BH, Henderson M, Wang L, Wu ZF, Wu HT, Jiang M, Lu XG (2018) Asymmetric effects of daytime and nighttime warming on spring phenology in the temperate grasslands of China. Agric For Meteorol 259:240-249

Shen XJ, Liu BH, Xue ZS, Jiang M, Lu XG, Zhang Q (2019) Spatiotemporal variation in vegetation 

spring phenology and its response to climate change in freshwater marshes of Northeast China. Sci Total Environ 666:1169-1177

Song LS, Li Y, Ren YH, Wu XC, Zhao L (2019) Divergent vegetation responses to extreme spring and summer droughts in southwestern china. Agric For Meteorol 279(279)

Suzuki R, Masuda K, Dye DG (2007)Interannual covariability between actual evapotranspiration and PAL and GIMMS NDVIs of northern Asia. Remote Sens Environ 106:387-398

Tang H, Dubayah R (2017) Light-driven growth in Amazon evergreen forests explained by seasonal variations of vertical canopy structure. Proc Natl Acad Sci 114:2640-2644

Tian YC, Bai XY, Wang SJ, Qin LY, Li Y (2017) Spatial-temporal Changes of Vegetation Cover in Guizhou Province, Southern China. Chinese Geogr Sci 27(1):25-38

Toms JD, Lesperance ML (2003) Piecewise regression: a tool for identifying ecological thresholds. Ecology 84(8)

Tong XW, Wang KL, Brandt M, Yue YM, Liao CJ, Fensholt R (2016) Assessing future vegetation trends and restoration prospects in the Karst Regions of Southwest China. Remote Sens 8:357

Tong XW, Wang KL, Yue YM, Brandt M, Liu B, Zhang CH, Liao CJ, Fensholt R (2017) Quantifying the effectiveness of ecological restoration projects on long-term vegetation dynamics in the karst regions of southwest china. Int J Appl Earth Obs 54:105-113

Tucker C, Pinzon J, Brown M, Slayback D, Pak E, Mahoney R, Vermote E, Saleous N (2005) An extended AVHRR 8-km NDVI dataset compatible with MODIS and SPOT vegetation NDVI data. Int J Remote Sens 26(20):4485-4498

Venter O, Sanderson EW, Magrach A, Allan JR, Beher J, Jones KR, Possingham HP, Laurance WF, Wood P, Fekete BM, Levy MA, Watson JEM (2016a) Sixteen years of change in the global 
615

616

617

618

619

620

621

622

623

624

625

626

627

628

629

630

631

632

633

634

635

636

terrestrial human footprint and implications for biodiversity conservation. Nat Commun 7(1):111

Venter O, Sanderson EW, Magrach A, Allan JR, Beher J, Jones KR, Possingham HP, Laurance WF, Wood P, Fekete BM, Levy MA, Watson JEM (2016b) Global terrestrial human footprint maps for 1993 and 2009. Scientific Data 3:160067

Wang H, Yao F, Zhu H, Zhao Y (2020) Spatiotemporal Variation of Vegetation Coverage and Its Response to Climate Factors and Human Activities in Arid and Semi-Arid Areas: Case Study of the Otindag Sandy Land in China. Sustainability 12(12):5214

Wang HQ, Sun BP, Yu XX, Xin ZB, Jia GD (2020) The driver-pattern-effect connection of vegetation dynamics in the transition area between semi-arid and semi-humid northern China. Catena 194:104713

Wang L, Wen C, Wen Z, Gang H (2015) Drought in southwest china: a review. Atmos. Oceanic Sci Lett 8(06):339-344

Wang W, Wang WJ, Li JS, Wu H, Xu C, Liu T (2010) The impact of sustained drought on vegetation ecosystem in southwest china based on remote sensing. Procedia Environ Sci 2(6):1679-1691

Wu CY, Hou XH, Peng DL, Gonsamo A, Xu SG (2016) Land surface phenology of china's temperate ecosystems over 1999-2013: spatial-temporal patterns, interaction effects, covariation with climate and implications for productivity. Agric For Meteorol 216:177-187

Wu L, Feng LP, Li YZ, Wang J, Wu LH (2019) A Yield-Related Agricultural Drought Index Reveals Spatio-Temporal Characteristics of Droughts in Southwestern China. Sustainability 11

Xiao JF (2014) Satellite evidence for significant biophysical consequences of the "grain for green" program on the loess plateau in china. J Geophys Res-Biogeo 119(12):2261-2275 
637

638

639

640

641

642

643

644

645

646

647

648

649

650

651

652

653

654

655

656

657

658

Xiong JN, Peng C, Cheng WM, Li WI, Liu ZQ, Fan CK, Sun HZ (2018) Analysis of vegetation coverage change in Yunnan province based on MODIS-NDVI (in Chinese). J Geo-Inf Sci 20(12):1830-1840

Yang YT, Guan HD, Shen MG, Liang W, Jiang L (2015) Changes in autumn vegetation dormancy onset date and the climate controls across temperate ecosystems in China from 1982 to 2010. Glob Chang Biol 21(2):652-665

Yao YT, Wang XH, Li Y, Wang T, Shen MG, Du MY, He HL, Li YN, Luo WJ, Ma MG, Ma YM, Tang YH, Wang HM, Zhang XZ, Zhang YP, Zhao L, Zhou GS, Piao S (2017) Spatiotemporal pattern of gross primary productivity and its covariation with climate in china over the last thirty years. Glob Chang Biol 24(1):184-196

Yin L, Dai EF, Zheng D, Wang YH, Ma L, Tong M (2020) What drives the vegetation dynamics in the Hengduan Mountain region, southwest China: Climate change or human activity? Ecol Indic 112

Yu S S, Zhang ZX, Liu F (2018) Monitoring population evolution in China using time-series DMSP/OLS nightlight imagery. Remote Sens 10(2):194

Yuan L, Bao Z, Zhang H, Zhang Y, Liang X (2017) Habitat monitoring to evaluate crop disease and pest distributions based on multi-source satellite remote sensing imagery. Optik 145:66-73

Zhang M, Cao CX, Chen W (2019) Remotely sensed diagnosing temporal and spatial variation of vegetation coverage in Guangxi based on MODIS NDVI Data (in Chinese). Sci Silvae Sin 55(10):27-37

Zhang XQ, Yamaguchi Y, Li F, He B, Chen YN (2017) Assessing the impacts of the 2009/2010 drought on vegetation indices, normalized difference water index, and land surface temperature 
660

661

662

663

664

665

666

667

668

669

670

671

672

673

674

Zhang Y, Zhang CB, Wang ZQ, Chen YZ, Gang CC, An R, Li JL (2016) Vegetation dynamics and its driving forces from climate change and human activities in the Three-River Source Region, China from 1982 to 2012. Sci Total Environ 563:210-220

Zhao AZ, Zhang AB, Liu JH, Feng LL, Zhao YL (2019) Assessing the effects of drought and "Grain for Green” Program on vegetation dynamics in China's Loess Plateau from 2000 to 2014. Catena 175:446-455

Zhao CH, Deng XZ, Yuan YW, Yan HM, Liang H (2013) Prediction of Drought Risk Based on the WRF Model in Yunnan Province of China. Adv Meteorol 2013:1-9

Zhao S, Pereira P, Wu XQ, Zhou JX, Cao JH, Zhang WX (2020) Global karst vegetation regime and its response to climate change and human activities. Ecol Indic 113:106208

Zhong QY, Ma J, Zhao B, Wang XX, Xiao X (2019) Assessing spatial-temporal dynamics of urban expansion, vegetation greenness and photosynthesis in megacity shanghai, china during 20002016. Remote Sens Environ 233:111374

Zoran MA, Zoran LFV, Dida AI (2016) Forest vegetation dynamics and its response to climate changes. Remote Sens. Agric Ecosyst Hydrol Xviii:9998 


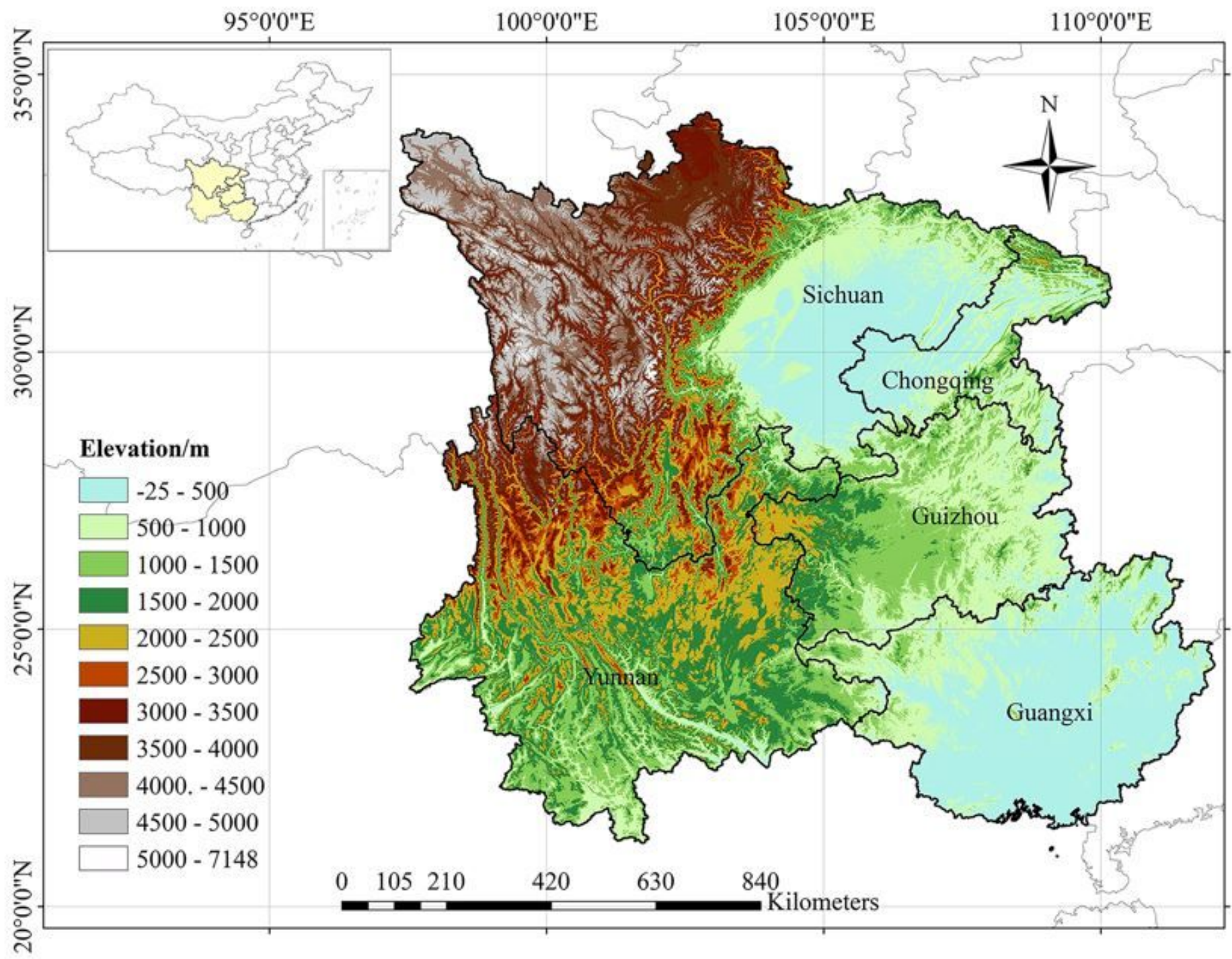

Figure 1

Location of Southwestern China and a digital elevation model (DEM) Note: The designations employed and the presentation of the material on this map do not imply the expression of any opinion whatsoever on the part of Research Square concerning the legal status of any country, territory, city or area or of its authorities, or concerning the delimitation of its frontiers or boundaries. This map has been provided by the authors. 

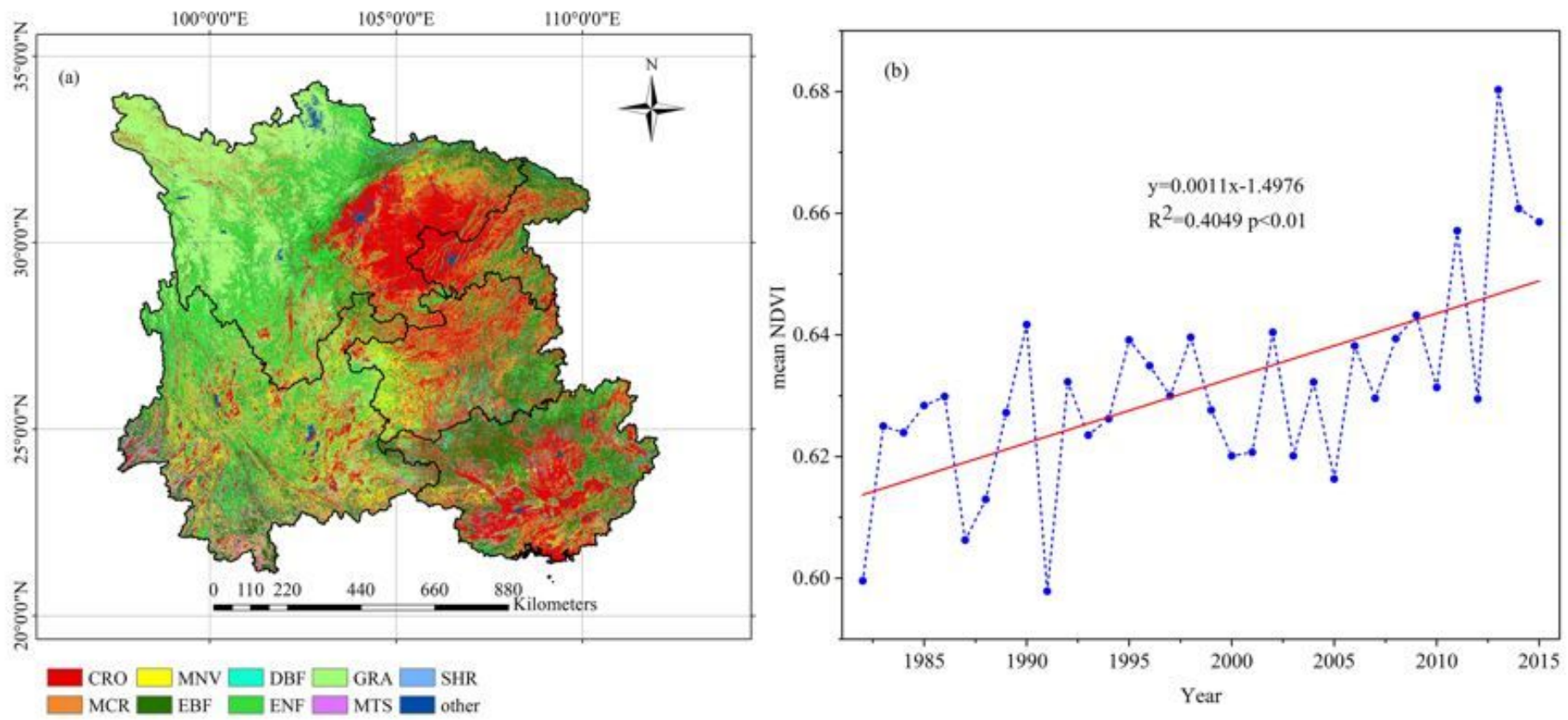

Figure 2

(a) Spatial distribution of vegetation types and (b) interannual change in mean NDVI in Southwestern China over the period 1982-2015. Vegetation types included rainfed and irrigated cropland (CRO); mixed cropland and natural vegetation, cropland $>50 \%$ (MCR); mixed natural vegetation and cropland, natural vegetation > 50\% (MNV); evergreen broad-leaved forest (EBF); deciduous broad-leaved forest (DBF); evergreen needle-leaved forest (ENF); grassland (GRA); mixed tree, shrub and herbaceous vegetation, tree and shrub > 50\% (MTS); shrubland (SHR); wetland, settlement, bare area and water (other). Note: The designations employed and the presentation of the material on this map do not imply the expression of any opinion whatsoever on the part of Research Square concerning the legal status of any country, territory, city or area or of its authorities, or concerning the delimitation of its frontiers or boundaries. This map has been provided by the authors. 

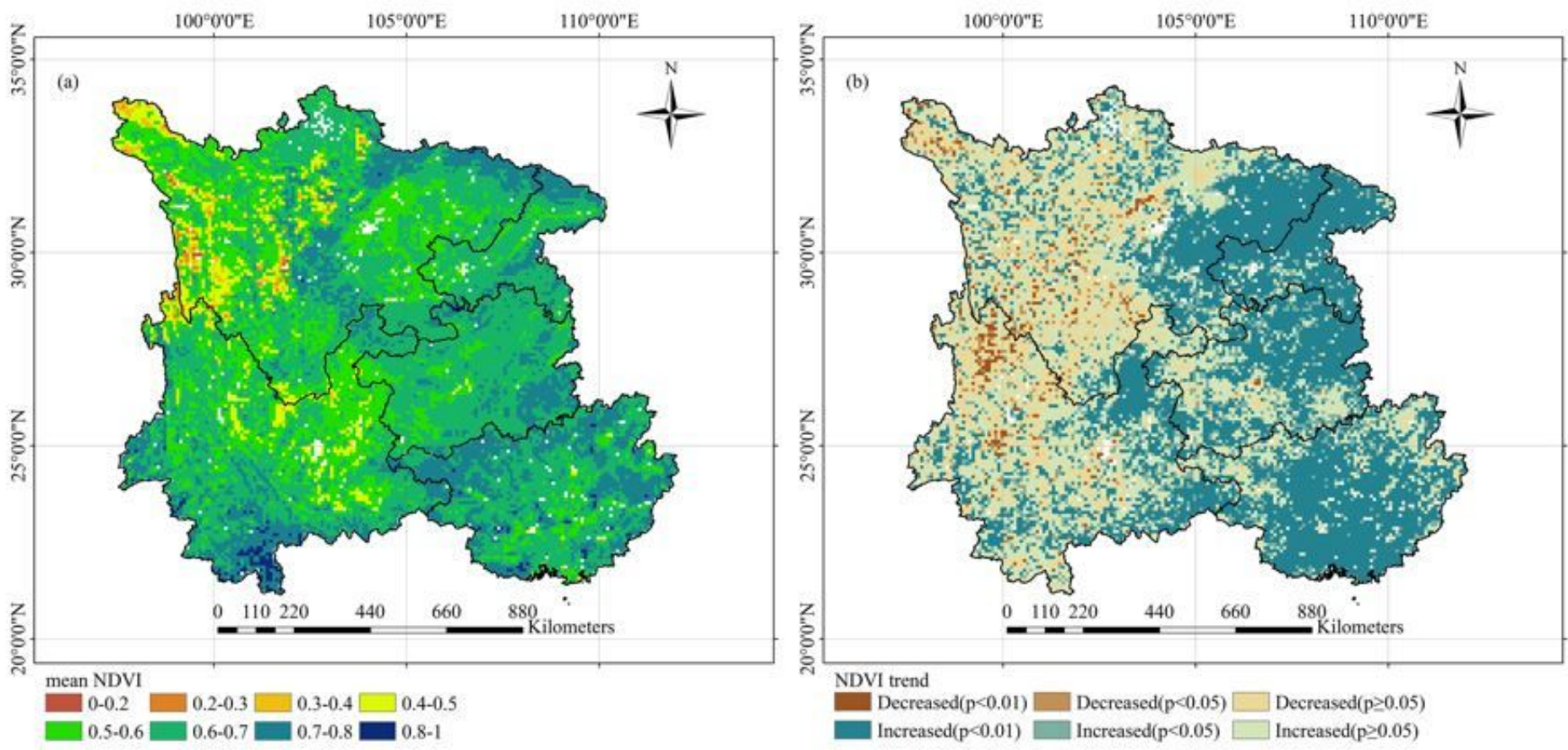

Figure 3

Spatial distribution of (a) the annual mean NDVI and (b) the NDVI trend over the period 1982-2015. Note: The designations employed and the presentation of the material on this map do not imply the expression of any opinion whatsoever on the part of Research Square concerning the legal status of any country, territory, city or area or of its authorities, or concerning the delimitation of its frontiers or boundaries. This map has been provided by the authors. 

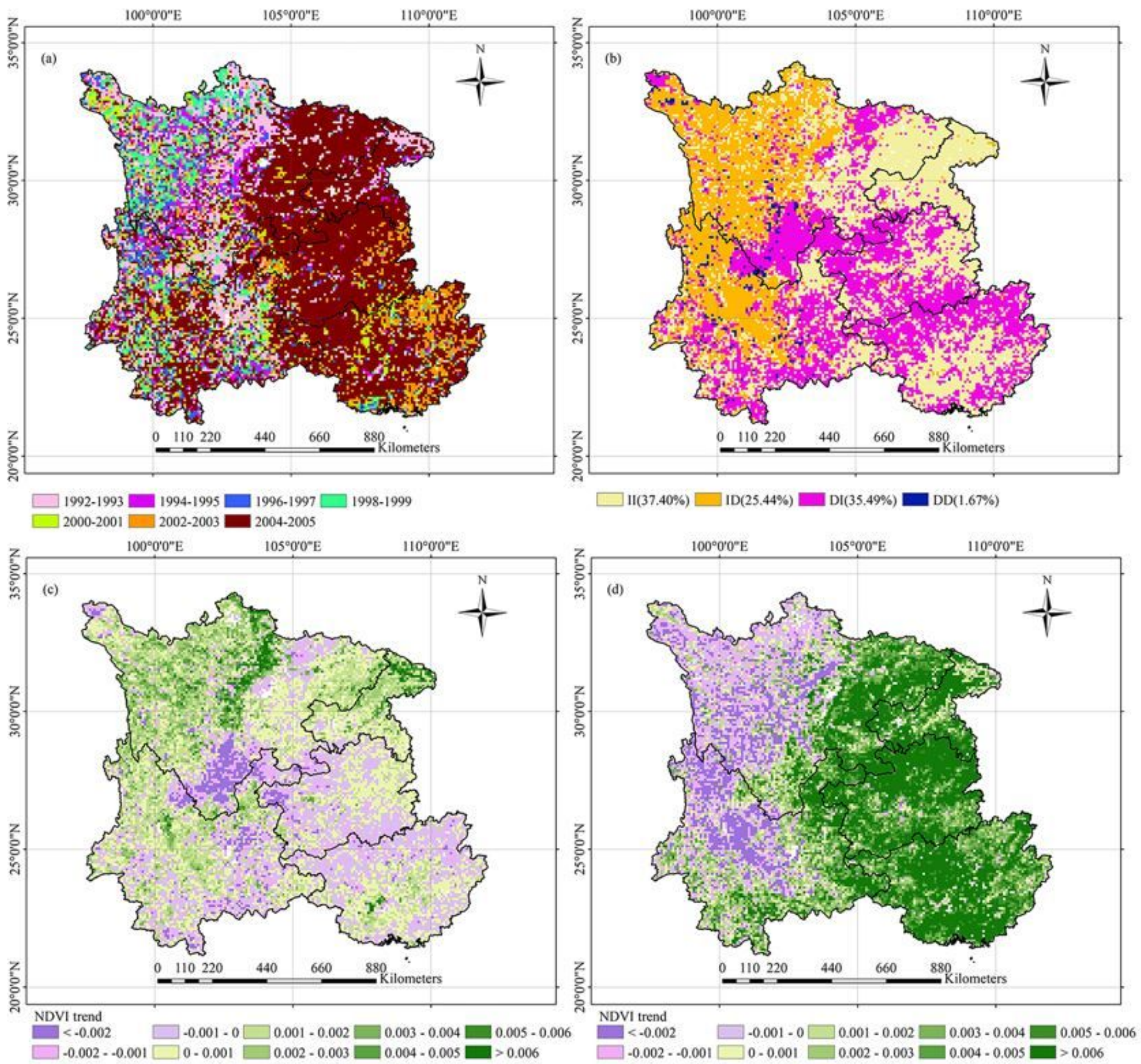

Figure 4

Spatial distribution of (a) the turning point year, (b) four types of NDVI changes: an increasing trend that continued to an increasing trend (II), an increasing trend that changed into a decreasing trend (ID), a decreasing trend that changed into an increasing trend (DI), a decreasing trend that continued to a decreasing trend (DD), (c) NDVI trend before that turning point year and (d) NDVI trend after that turning point year. Note: The designations employed and the presentation of the material on this map do not imply the expression of any opinion whatsoever on the part of Research Square concerning the legal status of any country, territory, city or area or of its authorities, or concerning the delimitation of its frontiers or boundaries. This map has been provided by the authors. 

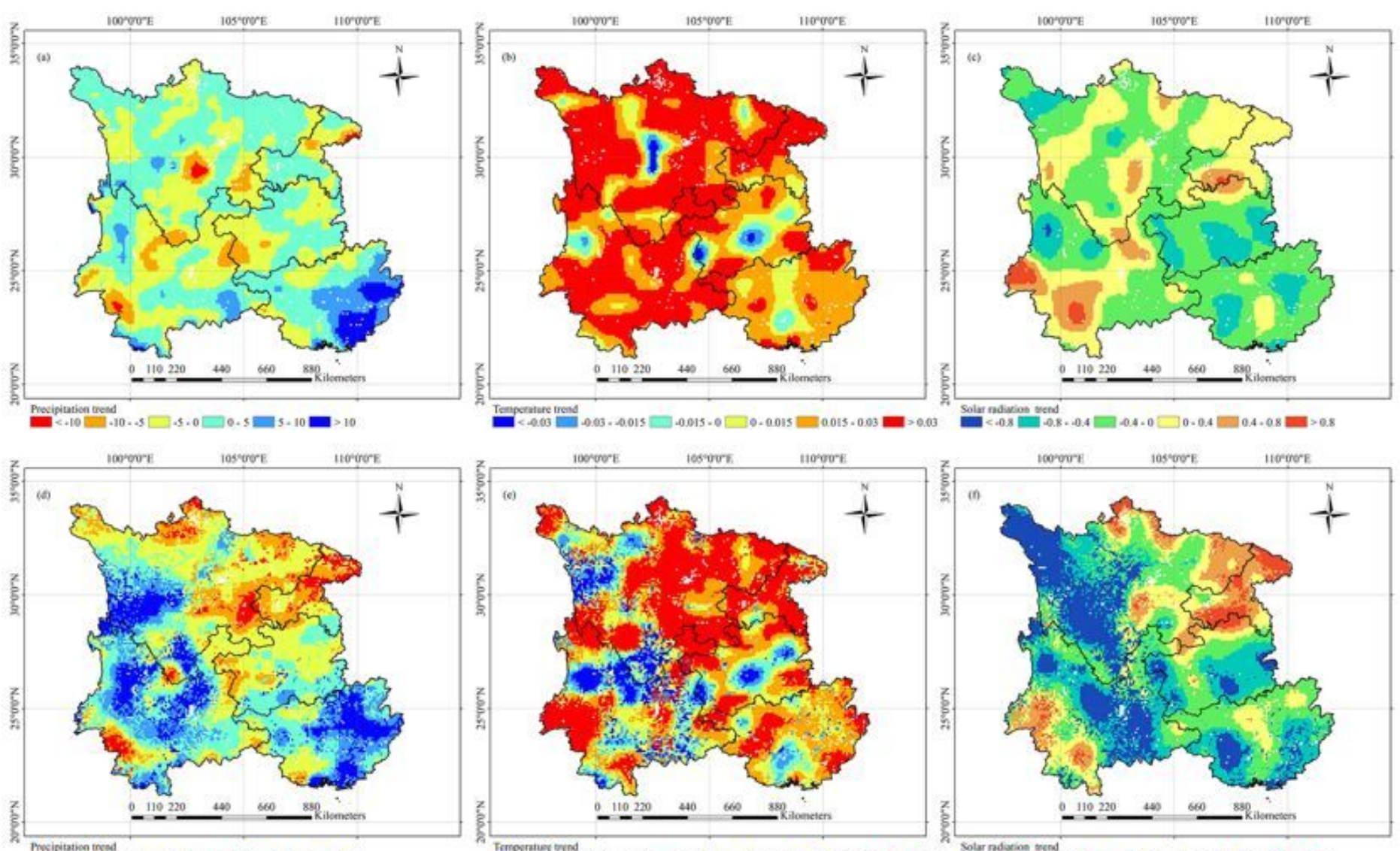

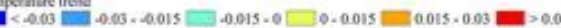
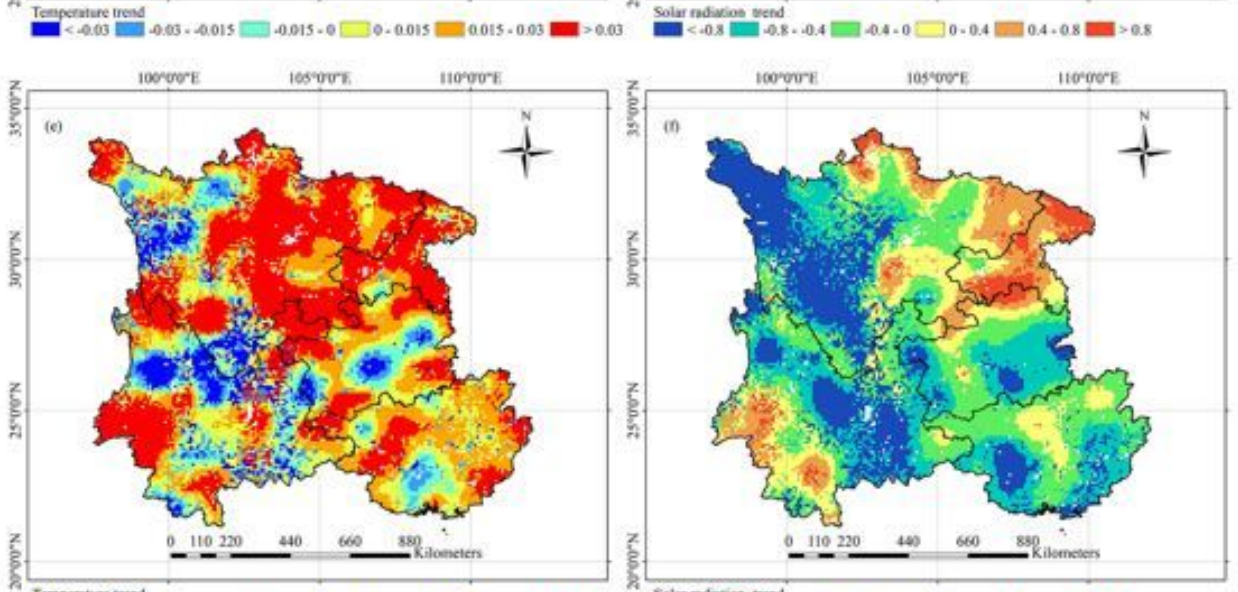

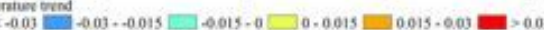
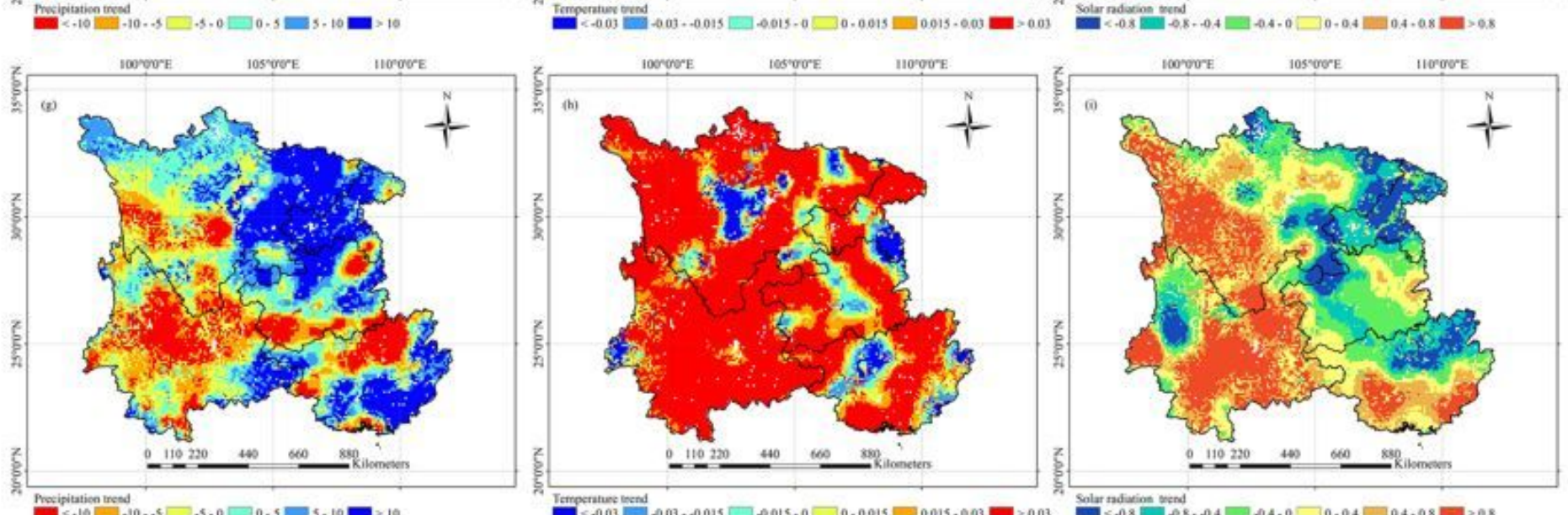

$<-10 \square-10-.5 \square-5-0 \square 0-5 \square 5-10 \square>16$

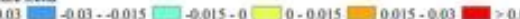

$-0.8 \square-0.8 \cdot-0.4 \square-0.4-0 \square \square-0.4 \square 0.4-0.8 \square>0.8$

\section{Figure 5}

Spatial distribution of (a) the precipitation trend, (b) temperature trend, (c) solar radiation trend over the period 1982-2015; (d) the precipitation trend, (e) temperature trend, $(\mathrm{f})$ solar radiation trend before the turning point; $(\mathrm{g})$ the precipitation trend, $(\mathrm{h})$ temperature trend, and (i) solar radiation trend after the turning point. Note: The designations employed and the presentation of the material on this map do not imply the expression of any opinion whatsoever on the part of Research Square concerning the legal status of any country, territory, city or area or of its authorities, or concerning the delimitation of its frontiers or boundaries. This map has been provided by the authors. 

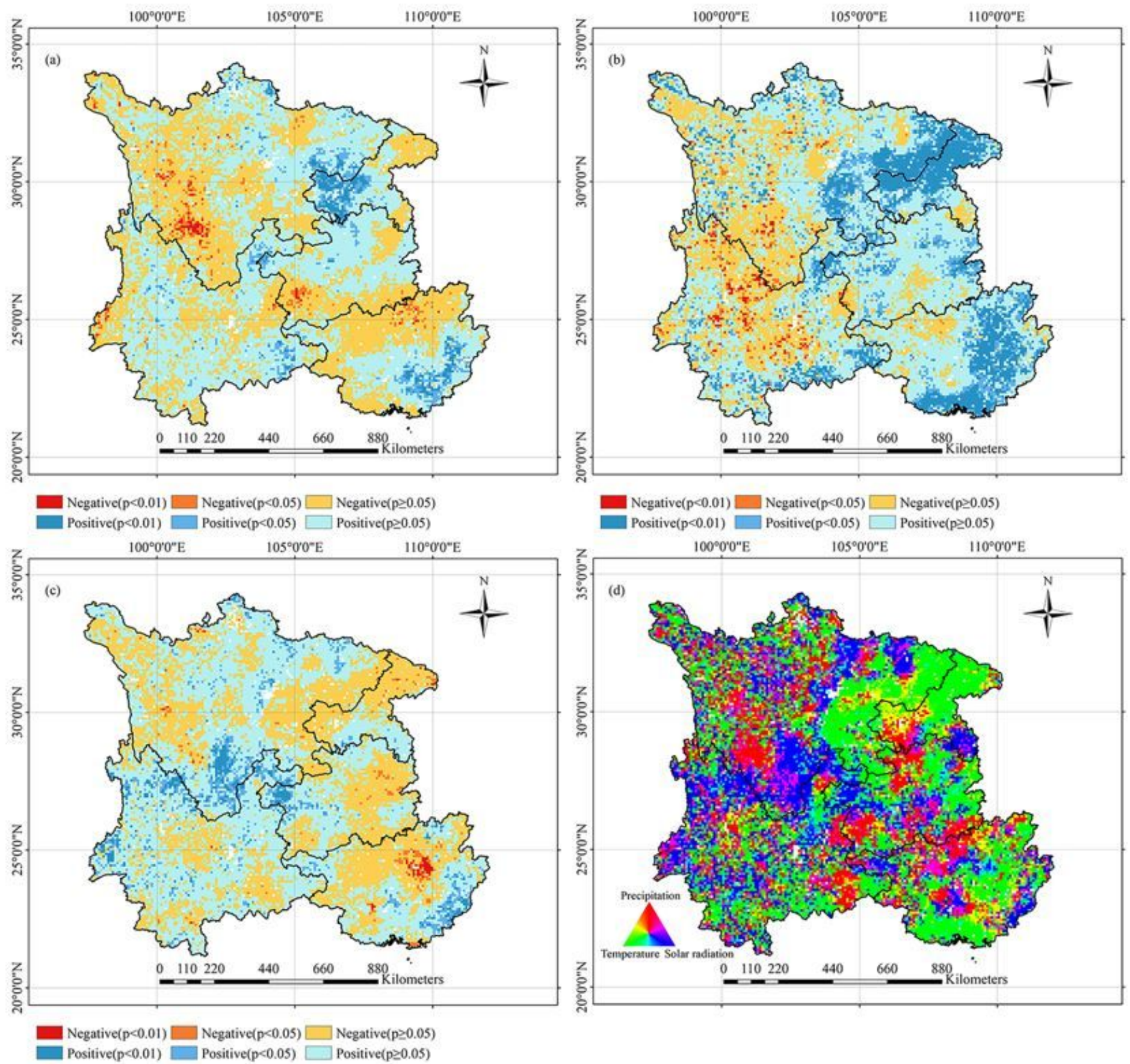

Figure 6

Spatial distribution of partial correlations between (a) mean NDVI and precipitation, (b) mean NDVI and temperature, (c) mean NDVI and solar radiation and (d) climate drivers of NDVI interannual variability. Note: The designations employed and the presentation of the material on this map do not imply the expression of any opinion whatsoever on the part of Research Square concerning the legal status of any country, territory, city or area or of its authorities, or concerning the delimitation of its frontiers or boundaries. This map has been provided by the authors. 

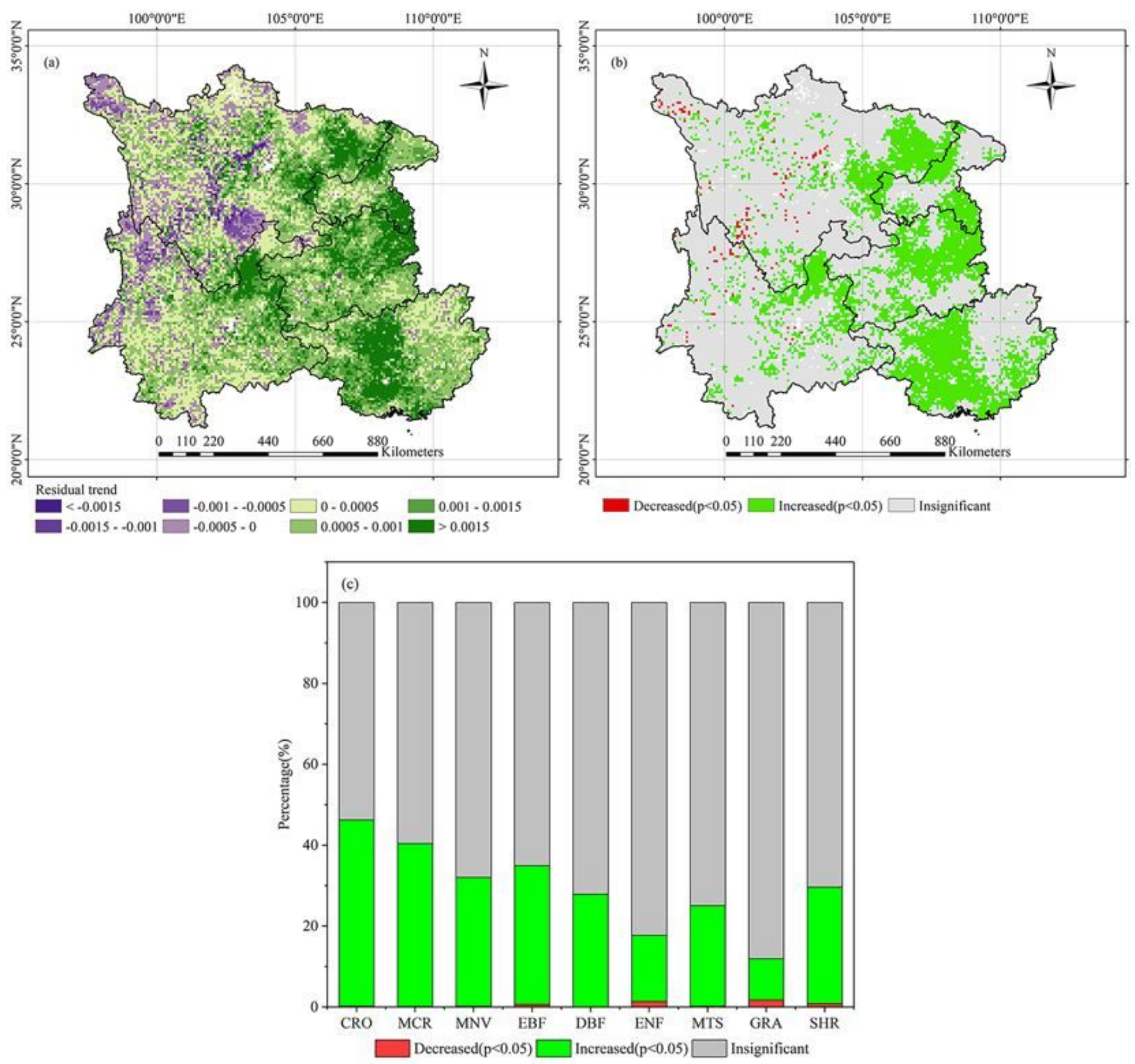

Figure 7

Spatial distribution of (a) NDVI residual trend and (b) residual trend types; (c) the percentage (\%) of different types of residual trend among vegetation types. Note: The designations employed and the presentation of the material on this map do not imply the expression of any opinion whatsoever on the part of Research Square concerning the legal status of any country, territory, city or area or of its authorities, or concerning the delimitation of its frontiers or boundaries. This map has been provided by the authors. 

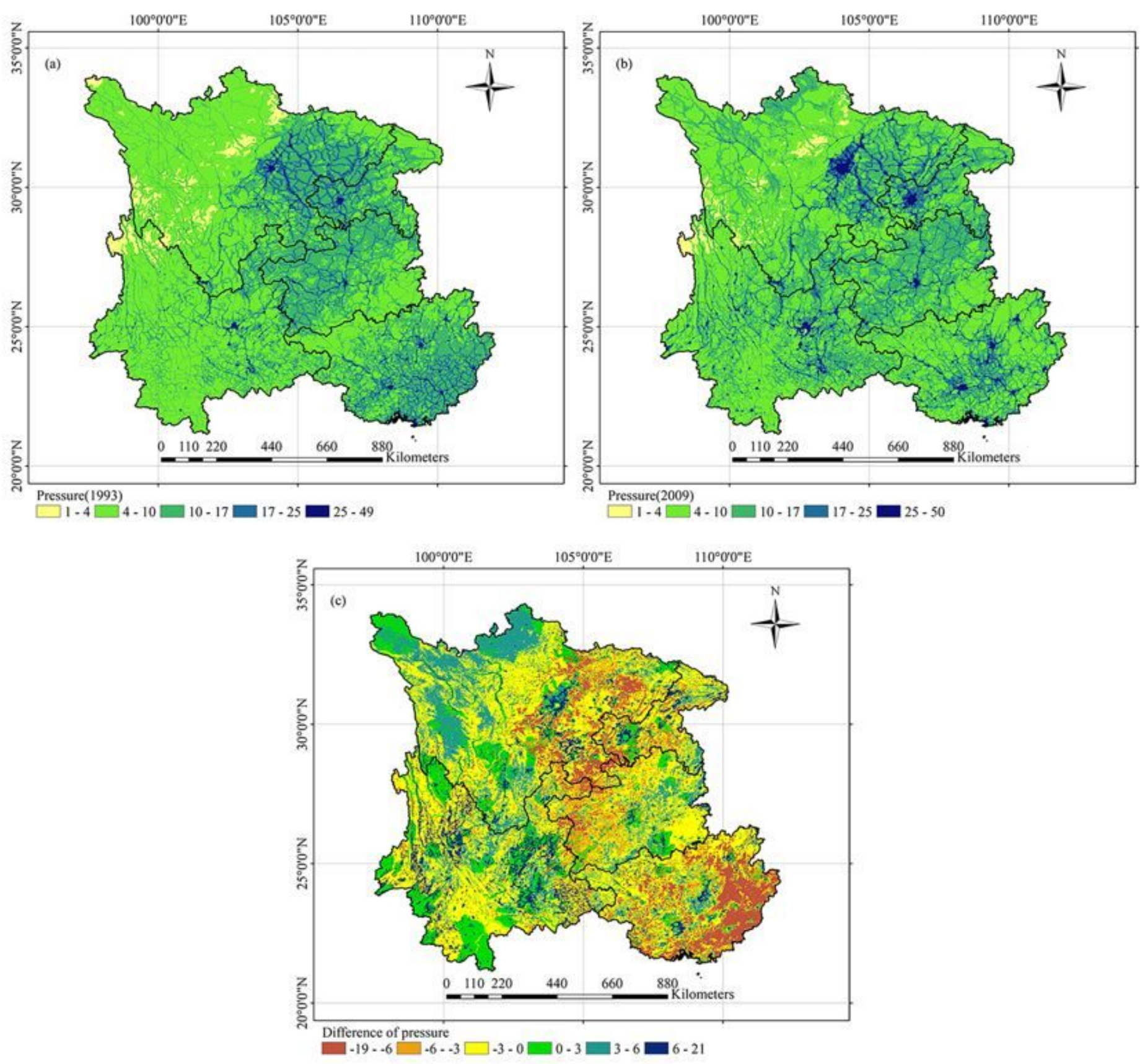

Figure 8

Spatial distribution of (a) the human footprint map for 1993, (b) the human footprint map for 2009, (c) difference in the human footprint map between 1993 and 2009. Note: The designations employed and the presentation of the material on this map do not imply the expression of any opinion whatsoever on the part of Research Square concerning the legal status of any country, territory, city or area or of its authorities, or concerning the delimitation of its frontiers or boundaries. This map has been provided by the authors. 